\title{
Haploidentical mixed chimerism cures autoimmunity in established type 1 diabetic mice
}

\author{
Yuqing Liu, ${ }^{1,2,3}$ Xiaoqi Wang, ${ }^{1,2,3}$ Yongping Zhu, ${ }^{1,2,4}$ Mingfeng Zhang, ${ }^{1,2}$ Ubaydah Nasri, ${ }^{1,2}$ Sharne S. Sun, ${ }^{5}$ Stephen J. Forman, ${ }^{2}$ \\ Arthur D. Riggs, ${ }^{1}$ Xi Zhang, ${ }^{3}$ and Defu Zeng ${ }^{1,2}$ \\ 'Diabetes and Metabolism Research Institute, and ${ }^{2}$ Hematologic Malignancies and Stem Cell Transplantation Institute, Beckman Research Institute of City of Hope, Duarte, California, USA. ${ }^{3}$ Medical Center \\ of Hematology, Xinqiao Hospital of Army Medical University, Chongqing, China. ${ }^{4}$ Department of Cardiovascular Surgery, Fujian Medical University Union Hospital, Fuzhou, China. ${ }^{5}$ Eugene and Ruth Roberts \\ Summer Student Academy of City of Hope, Duarte, California, USA.
}

\begin{abstract}
Clinical trials are currently testing whether induction of haploidentical mixed chimerism (Haplo-MC) induces organ transplantation tolerance. Whether Haplo-MC can be used to treat established autoimmune diseases remains unknown. Here, we show that established autoimmunity in euthymic and adult-thymectomized NOD $\left(\mathrm{H}-2^{\mathrm{g}}\right)$ mice was cured by induction of Haplo-MC under a non-myeloablative anti-thymocyte globulin-based conditioning regimen and infusion of CD4+ $T$ celldepleted hematopoietic graft from $\mathrm{H}-2^{\mathrm{b} / \mathrm{g}^{7}} \mathrm{~F}_{1}$ donors that expressed autoimmune-resistant $\mathrm{H}-2^{\mathrm{b}}$ or from $\mathrm{H}-2^{5 / \mathrm{g}^{7}} \mathrm{~F}_{1}$ donors that expressed autoimmune-susceptible $\mathrm{H}-2^{\mathrm{s}}$. The cure was associated with enhanced thymic negative selection, increased thymic Treg (tTreg) production, and anergy or exhaustion of residual host-type autoreactive T cells in the periphery. The peripheral tolerance was accompanied by expansion of donor- and host-type CD62L-Helios ${ }^{+}$tTregs as well as host-type Helios-Nrp1+ peripheral Tregs (pTregs) and PD-L1 hi plasmacytoid DCs (pDCs). Depletion of donor- or host-type Tregs led to reduction of host-type PD-L1 ${ }^{\text {hi }}$ pDCs and recurrence of autoimmunity, whereas PD-L1 deficiency in host-type DCs led to reduction of hosttype pDCs and Helios-Nrp1+ ${ }^{+}$Tregs. Thus, induction of Haplo-MC reestablished both central and peripheral tolerance through mechanisms that depend on allo-MHC+ donor-type DCs, PD-L1 hi host-type DCs, and the generation and persistence of donorand host-type tTregs and pTregs.
\end{abstract}

\section{Introduction}

Haploidentical hematopoietic cell transplantation (Haplo-HCT) has been widely applied to the treatment of hematological malignancies and nonmalignant disorders (1). Induction of haploidentical mixed chimerism (Haplo-MC) for organ transplantation immune tolerance is in clinical trials (ClinicalTrials.gov NCT03292445, NCT01165762, NCT01780454, NCT02314403, NCT00801632, NCT01758042), and the results are promising $(2-5)$. However, it remains unclear whether induction of Haplo-MC can reverse autoimmunity, because induction of MHC-matched or HLA-matched mixed chimerism is not able to reverse autoimmunity in type 1 diabetic (T1D) mice or systemic lupus erythematosus (SLE) in humans (6-8).

The essential pathogenesis of autoimmune diseases (i.e., T1D and SLE) lies in the abnormalities of the hematopoietic stem cells $(9,10)$, because an autoimmune disease can be transferred from potential autoimmune patients into non-autoimmune patients via HLA-matched allogeneic HCT (11). The abnormalities of hematopoietic stem cells can lead to development of defective central and peripheral immune tolerance mechanisms that allow develop-

Authorship note: $\mathrm{YL}, \mathrm{XW}$, and $\mathrm{YZ}$ contributed equally to this work Conflict of interest: The authors have declared that no conflict of interest exists. Copyright: @ 2020, American Society for Clinical Investigation. Submitted: July 31, 2019; Accepted: August 13, 2020; Published: November 3, 2020 Reference information: J Clin Invest. 2020;130(12):6457-6476. https://doi.org/10.1172/JCl131799. ment of systemic or organ-specific autoimmune diseases including T1D, SLE, and multiple sclerosis (12).

The NOD mouse model has provided invaluable understanding of basic immune pathogenesis, genetic and environmental risk factors, and immune targeting strategies $(13,14)$. Hematopoietic stem cells from NOD mice give rise to thymic medullary dendritic cells (DCs) that express $\mathrm{I}-\mathrm{A}^{\mathrm{g} 7}$ that cannot mediate effective negative selection of autoreactive $\mathrm{T}$ cells or effective production of thymic Tregs (tTregs), leading to defective function of tTregs and loss of tolerogenic features of dendritic cells in the periphery $(15,16)$, including tolerogenic PD-L1 ${ }^{\text {hi }}$ plasmacytoid DCs (pDCs) becoming non-tolerogenic PD-L $1^{\text {lo }}$ pDCs. Owing to these defects, costimulatory blockade could not induce transplantation immune tolerance in NOD mice (17).

Our series of publications on murine models have demonstrated that induction of full MHC-mismatched mixed chimerism cures established autoimmune diseases such as T1D, systemic lupus, and multiple sclerosis without causing graft-versus-host disease (GVHD) (18-22). Unfortunately, full HLA-mismatched HCT is not yet applicable in the clinic. Therefore, we tested whether induction of Haplo-MC reversed established autoimmunity in T1D mice. Using a non-myeloablative conditioning regimen of anti-thymocyte globulin (ATG) plus cyclophosphamide (CY) plus pentostatin (PT) and infusion of donor $\mathrm{CD}^{+} \mathrm{T}$ cell-depleted hematopoietic transplant, as described previously (22), we observed that induction of Haplo-MC cured established T1D in both euthymic and adult-thymectomized NOD mice through reestablishing both central and peripheral tolerance. 


\section{Results}

Induction of Haplo-MC cures autoimmunity in established T1D euthymic NOD mice. When autoimmune-resistant $\mathrm{H}-2^{\mathrm{b}}$ were backcrossed to NOD mice, the $\mathrm{H}-2^{\mathrm{b} / \mathrm{g} 7}$ NOD mice no longer developed T1D; but when autoimmune-susceptible $\mathrm{H}-2^{\mathrm{s}}$ were backcrossed to NOD mice, the H-2 ${ }^{s / g 7}$ NOD mice still developed T1D (23). Therefore, we tested whether induction of Haplo-MC with $\mathrm{H}-2^{\mathrm{b} / \mathrm{g} 7}$ or $\mathrm{H}-2^{\mathrm{s} / \mathrm{g} 7} \mathrm{~F}_{1}$ donors could cure autoimmunity in both prediabetic and new-onset diabetic NOD mice.

Nine- to 12-week-old prediabetic NOD mice were conditioned with ATG + CY + PT, as previously described $(22,24)$, and underwent transplantation of bone marrow $(\mathrm{BM})\left(50 \times 10^{6}\right)$ and spleen cells $\left(30 \times 10^{6}\right)$ from $\mathrm{H}-2^{\mathrm{b} / \mathrm{g} 7}$ or $\mathrm{H}-2^{\mathrm{s} / \mathrm{g} 7} \mathrm{~F}_{1}$ donors, with coinjection of depleting anti-CD4 mAb $(500 \mu \mathrm{g} /$ mouse) to prevent acute GVHD, as previously described (25). Both haploidentical transplants resulted in stable Haplo-MC in blood, and the mixed chimerism was confirmed at the end of experiments at 100 days after HCT (Supplemental Figure 1; supplemental material available online with this article; https://doi.org/10.1172/JCI131799DS1). The mixed chimeras showed no signs of clinical GVHD as judged by their healthy appearance and stable body weight and no histopathological damage in GVHD target organs including liver and lung (Supplemental Figure 2). While 65\% of NOD mice given conditioning alone developed hyperglycemia, and the residual mice without hyperglycemia showed severe insulitis, both recipients with $\mathrm{H}-2^{\mathrm{b} / \mathrm{g} 7}$ and recipients with $\mathrm{H}-2^{\mathrm{s} / \mathrm{g} 7}$ Haplo-MC showed normal glycemia for more than 100 days after HCT and showed little insulitis at the end of experiment (Figure 1, A-C). These results indicate that both $\mathrm{H}-2^{\mathrm{b} / \mathrm{g} 7}$ and $\mathrm{H}-2^{\mathrm{s} / \mathrm{g} 7}$ Haplo-MC can prevent T1D development and eliminate insulitis.

Second, we induced Haplo-MC in new-onset T1D NOD mice with blood glucose greater than $400 \mathrm{mg} / \mathrm{dL}$ for 3 consecutive days, as previously described (20). Both $\mathrm{H}-2^{\mathrm{b} / \mathrm{g} 7}$ and $\mathrm{H}-2^{\mathrm{s} / \mathrm{g} 7} \mathrm{Hap}-$ lo-MC normalized blood glucose with little insulitis in new-onset diabetic NOD mice (Figure 1, D-F). Although conditioning alone was able to normalize blood glucose in many new-onset recipients, which is consistent with previous reports $(20,26,27)$, those mice still had severe insulitis (Figure 1, D-F).

Induction of Haplo-MC cures autoimmunity in adult-thymectomized NOD mice. We also tested whether functional thymus was required for prevention of T1D and elimination of insulitis in Haplo-MC. Since NOD mice thymectomized as adults (i.e., at 6 weeks old) (Thymec-NOD mice) developed T1D (28), we tested whether induction of Haplo-MC in adult Thymec-NOD mice cured T1D. Since induction of mixed chimerism with autoimmune-resistant $\mathrm{H}-2^{\mathrm{b} / \mathrm{g} 7} \mathrm{~F}_{1}$ versus autoimmune-susceptible $\mathrm{H}-2^{\mathrm{s} / \mathrm{g} 7}$ $\mathrm{F}_{1}$ donors was equally effective at curing T1D in NOD mice, we only tested induction of mixed chimerism with $\mathrm{H}-2^{\mathrm{s} / \mathrm{g} 7} \mathrm{~F}_{1}$ donors in the adult Thymec-NOD mice. The same conditioning regimen of ATG + CY + PT used for euthymic NOD mice was applied to adult Thymec-NOD mice at the age of about 10 weeks, that is, about 4 weeks after thymectomy. The mice were injected with whole $\mathrm{BM}\left(50 \times 10^{6}\right)$ from $\mathrm{H}-2^{\mathrm{s} / \mathrm{g} 7} \mathrm{~F}_{1}$ donors. The recipients developed stable mixed chimerism as indicated by coexistence of donor- and host-type T cells, B cells, macrophages, and granulocytes in the blood, spleen, and BM at 80 days after HCT, the end of experiments (Supplemental Figure 4, A-C). While 60\% of untreated Thymec-NOD mice developed hyperglycemia, the mice given conditioning alone or given induction of Haplo-MC did not develop T1D (Supplemental Figure 5A). The untreated mice with euglycemia still showed severe insulitis (Supplemental Figure 5, B and C). Interestingly, conditioning alone markedly reduced insulitis, and induction of Haplo-MC further cleared insulitis (Supplemental Figure 5, B and C). These results indicate that conditioning with ATG $+\mathrm{CY}+\mathrm{PT}$ alone is able to prevent T1D development with marked reduction of insulitis in adult-thymectomized NOD mice; and induction of Haplo-MC totally eliminates residual insulitis.

Induction of Haplo-MC in NOD mice conditioned with lethal total-body irradiation prevents clinical T1D development but is not able to eliminate insulitis. Furthermore, we tested whether induction of Haplo-MC with myeloablative total-body irradiation (950 cGy TBI) conditioning and transplantation of $\mathrm{T}$ cell-depleted BM (TCD-BM), as previously described (29), could prevent T1D development. Lethal TBI-conditioned NOD mice subjected to transplantation of syngeneic NOD TCD-BM alone $\left(5 \times 10^{6}\right)$ were used as control. Haplo-MC was induced by transplantation of TCD-BM from NOD mice $\left(5 \times 10^{6}\right.$ cells $)$ and from $\mathrm{H}-2^{\mathrm{b} / \mathrm{g} 7}$ or $\mathrm{H}-2^{\mathrm{s} / \mathrm{g} 7}$ $\mathrm{F}_{1}$ donors $\left(7.5 \times 10^{6}\right.$ cells $)$. The recipients given $\mathrm{H}-2^{\mathrm{b} / \mathrm{g} 7}$ or $\mathrm{H}-2^{\mathrm{s} / \mathrm{g} 7}$ TCD-BM cells developed stable mixed chimerism as indicated by coexistence of donor- and host-type $\mathrm{T}$ cells, B cells, macrophages, and granulocytes in the peripheral blood, spleen, and BM (Supplemental Figure 6). While 50\% (7/14) of control recipients developed T1D with hyperglycemia at about 40 days after HCT, none of the mixed chimeras developed T1D by 80 days after HCT (Supplemental Figure 7A). The residual control recipients with euglycemia had more than $60 \%$ of residual islets showing severe insulitis (Supplemental Figure 7, B and C). Surprisingly, although there was a reduction in insulitis, the mixed chimeras still had more than $30 \%$ of islets showing severe insulitis (Supplemental Figure $7 \mathrm{C}$ ). These results indicate that induction of mixed chimerism with TCD-BM is able to control T1D development, but not able to eliminate insulitis.

Taken together, the above results indicate the following: (a) Induction of Haplo-MC via non-myeloablative conditioning with $\mathrm{CY}+\mathrm{PT}+\mathrm{ATG}$ and transplantation with $\mathrm{CD} 4^{+} \mathrm{T}$ cell-depleted graft cures established T1D with elimination of insulitis in prediabetic euthymic and adult-thymectomized as well as new-onset diabetic NOD mice. (b) Induction of Haplo-MC in lethal TBIconditioned NOD mice given donor TCD-BM cells is not able to cure T1D autoimmunity with elimination of insulitis. In light of a theory proposed by Sykes and colleagues that graft-versus-autoimmune-cells (GVA) activity is important for cure of autoimmunity after allogeneic HCT (12), we speculate that the lack of cure in the lethal TBI-conditioned Haplo-MC NOD mice may result from transplantation of donor TCD-BM cells that have little GVH and GVA activity. The following mechanistic studies were focused on how Haplo-MC cures autoimmunity in euthymic and thymectomized NOD mice conditioned with the non-myeloablative regimen of ATG + CY + PT.

Haplo-MC in euthymic NOD mice augments thymic negative selection of host-type thymocytes. Autoimmune NOD mice have defects in thymic negative selection $(30,31)$. Backcross of protective $\mathrm{H}-2^{\mathrm{b}}$ but not autoimmune-susceptible $\mathrm{H}-2^{\mathrm{s}}$ to NOD mice was able to 
A
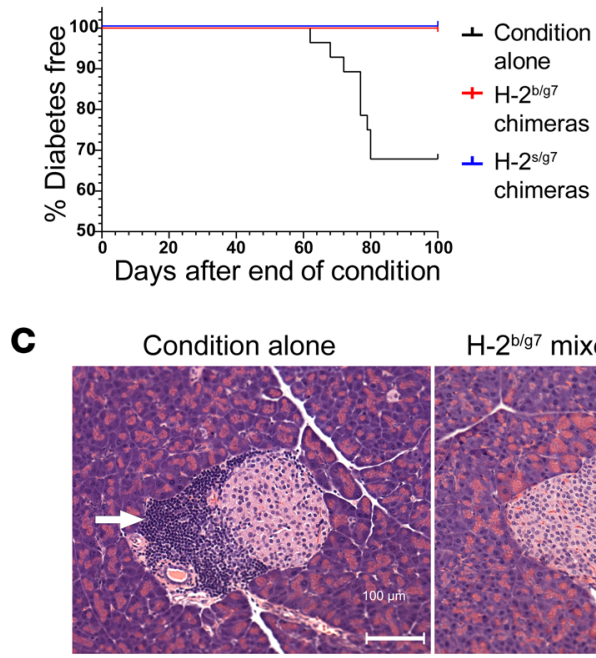

$\mathrm{H}-2^{\mathrm{b} / \mathrm{g} 7}$ mixed chimeras

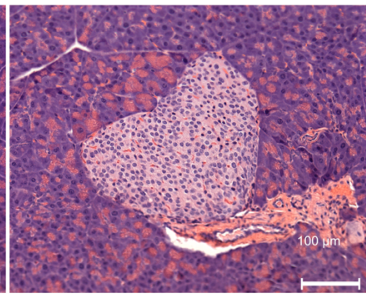

D

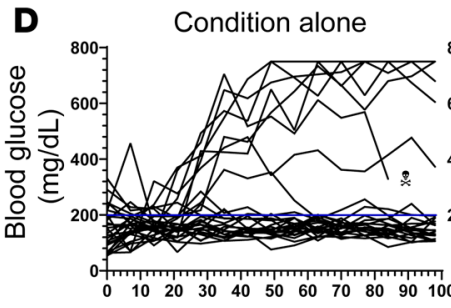

$\mathrm{H}-2^{\mathrm{b} / \mathrm{9} 7}$ mixed chimeras
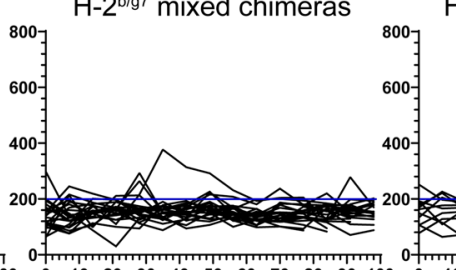

$\mathrm{H}-2^{\mathrm{s} / \mathrm{g} 7}$ mixed chimeras

Days after end of condition

Days after end of condition

E

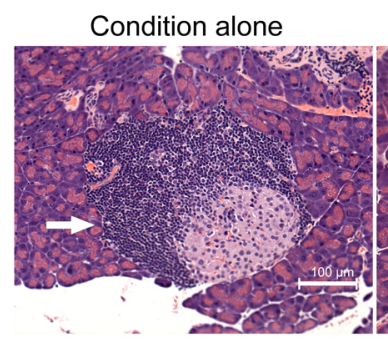

$\mathrm{H}-2^{\mathrm{b} / \mathrm{g} 7}$ mixed chimeras

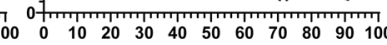
Days after end of condition

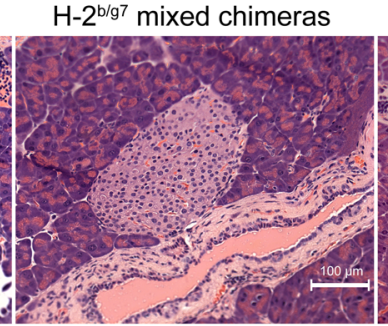

$\mathrm{H}-2^{\mathrm{s} / \mathrm{g} 7}$ mixed chimeras

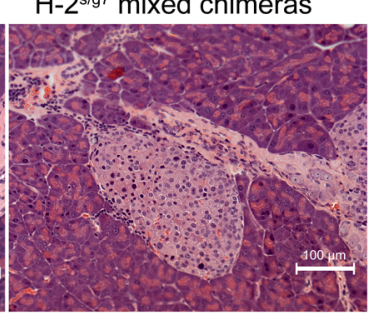

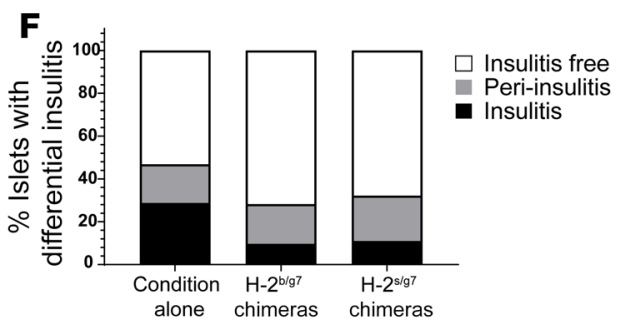

restore negative selection (23). We tested whether Haplo-MC with $\mathrm{H}-2^{\mathrm{b} / \mathrm{g} 7}$ or $\mathrm{H}-2^{\mathrm{s} / \mathrm{g} 7}$ donors can restore thymic deletion of host-type autoreactive T cells. To avoid the confounding effects of hyperglycemia, we used prediabetic NOD mice that still have normal glycemia to evaluate the impact of Haplo-MC on thymocyte generation.

We found that the percentage of donor-type $\mathrm{CD} 4^{+} \mathrm{CD} 8^{+}(\mathrm{DP})$ thymocytes in the Haplo-MC NOD mice was more than 75\%, similar to that of healthy donors (Figure 2A). This normal percentage of donor-type DP thymocytes suggests that there is no GVHD damage of thymus. The percentage of host-type DP thymocytes in the NOD mice given conditioning alone was more than $80 \%$; however, the percentage of host-type DP thymocytes in the $\mathrm{H}-2^{\mathrm{b} / \mathrm{g} 7}$ or $\mathrm{H}-2^{\mathrm{s} / \mathrm{g} 7}$ Haplo-MC was significantly reduced, the average being
$51.21 \%$ and $43.70 \%$, respectively (Figure $2 \mathrm{~A}$ ). These results suggest that Haplo- $\mathrm{MC}$ with either $\mathrm{H}-2^{\mathrm{b} / \mathrm{g} 7}$ or $\mathrm{H}-2^{\mathrm{s} / \mathrm{g} 7}$ donors can restore negative selection in the thymus.

To further test whether $\mathrm{H}-2^{\mathrm{b} / \mathrm{g} 7}$ or $\mathrm{H}-2^{\mathrm{s} / \mathrm{g} 7}$ Haplo-MC mediated deletion of autoreactive DP thymocytes, we induced Haplo-MC in BDC2.5 NOD mice as described in Supplemental Figure 3. Both $\mathrm{H}-2^{\mathrm{b} / \mathrm{g} 7}$ and $\mathrm{H}-2^{\mathrm{s} / \mathrm{g} 7}$ Haplo-MC depleted almost all DP thymocytes in BDC2.5 NOD mice (Figure 2B). In addition, autoreactive T cells often express dual T cell receptor- $\alpha$ (TCR $\alpha)(32,33)$. The V $\alpha 1 \mathrm{~V} \beta 4$ transgenic $\mathrm{CD}^{+}{ }^{+} \mathrm{T}$ cells can express the second TCR with endogenous $\mathrm{V} \alpha 2\left(\mathrm{~V} \alpha 2^{+} \mathrm{V} \beta 4^{+}\right)(32)$. We observed that the $\mathrm{V} \beta 4^{+}$transgenic $\mathrm{CD}^{+} \mathrm{T}$ cells with endogenous $\mathrm{V} \alpha 2^{+}$among residual $\mathrm{CD}^{+} \mathrm{CD}^{-}$ (SP) thymocytes were markedly reduced (Figure $2 \mathrm{C}$ ). These results 
A

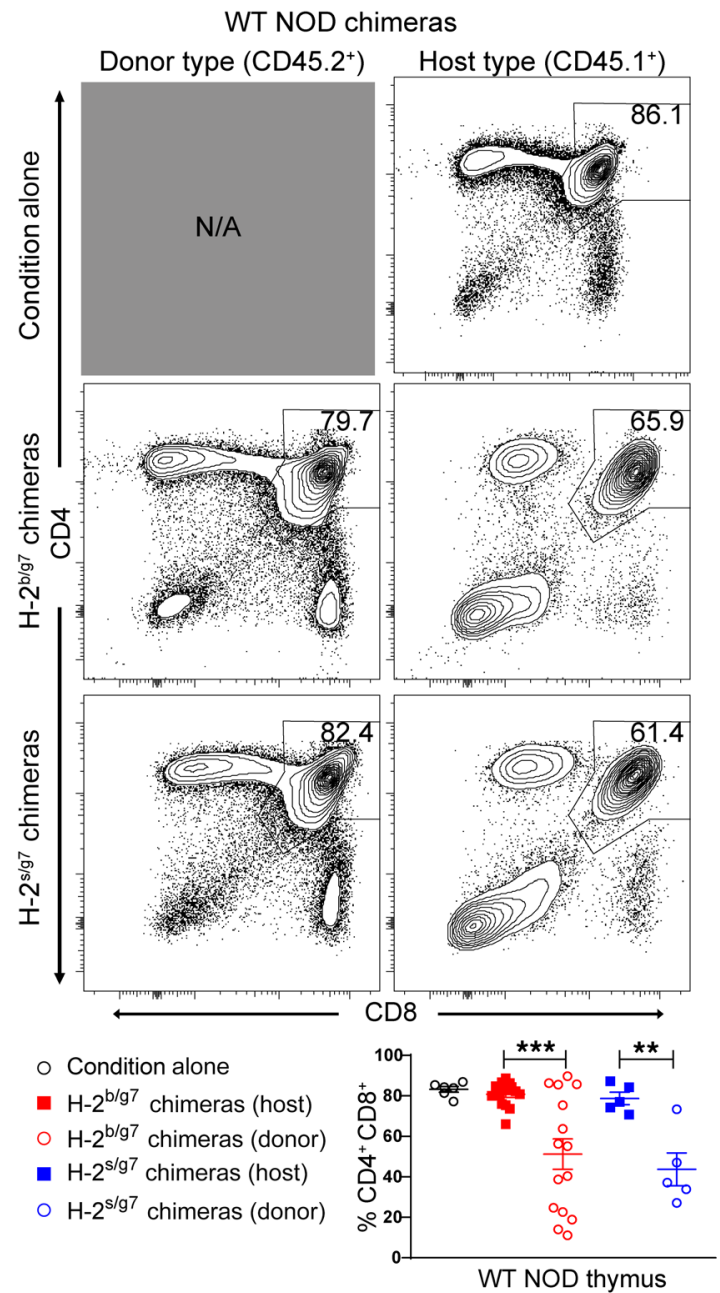

B

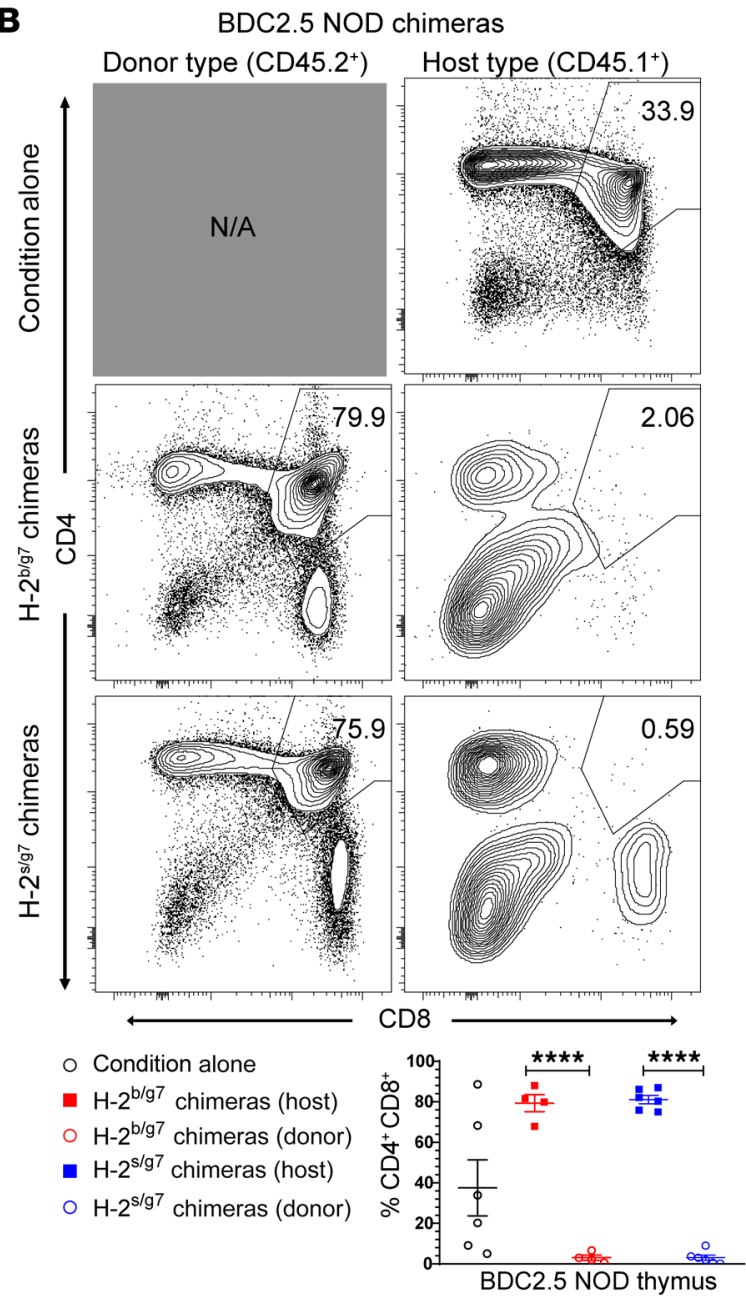

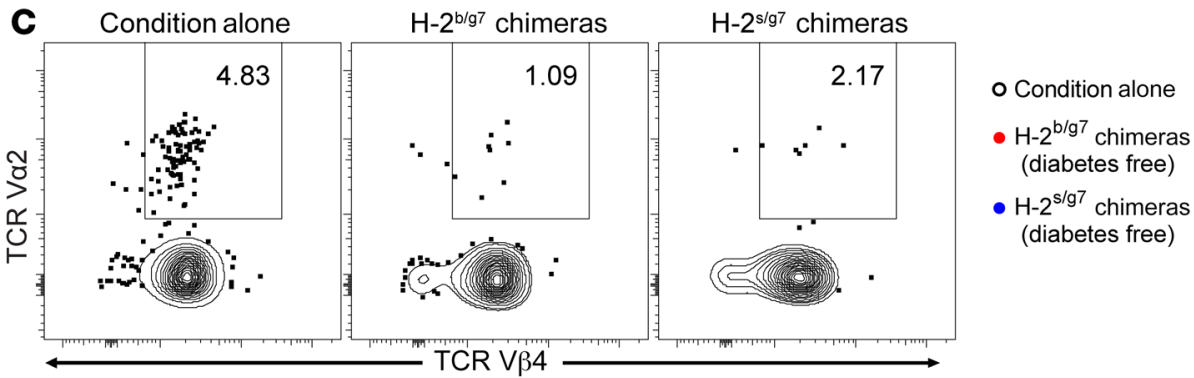

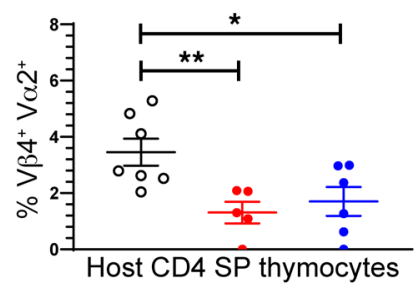

Figure 2. Haplo-MC reduces host-type CD4+CD8+ thymocytes and thymocytes with dual TCRs. Sixty days after HCT, thymocytes from mixed chimeric WT NOD and BDC2.5 NOD mice or control mice given conditioning alone were analyzed for donor- and host-type CD4+CD8 ${ }^{+}$thymocytes. (A and B) Thymocytes of WT NOD and BDC2.5 NOD are shown for donor- and host-type CD4+CD8+, respectively ( $n=6-15)$. (C) The BDC2.5 transgenic TCR consists of $V \alpha 1$ and $V \beta 4$. If a $V \beta 4^{+} T$ cell also expresses any $V \alpha$ chain other than $V \alpha 1$, such as $V \alpha 2$, it is considered as a $T$ cell expressing more than one set of TCRs. Representative staining and summary (mean \pm SEM) of percentage T cells with dual TCRs among the host-type CD4+CD8- population in BDC2.5 thymus are shown ( $n=$ 5-7). $P$ values were calculated using unpaired 2-tailed Student's $t$ tests (A and $\mathbf{B})$ or 1 -way ANOVA $(\mathbf{C}) ;{ }^{*} P<0.05,{ }^{* *} P<0.01,{ }^{* * *} P<0.001,{ }^{* * * *} P<0.0001$.

indicate that induction of Haplo-MC augments negative selection of host-type thymocytes, including autoreactive thymocytes.

Haplo-MC in euthymic NOD mice augments thymic generation of host- and donor-type Foxp $3^{+}$tTregs. Augmentation of negative selection of conventional thymocytes is often accompanied by enhanced tTreg production (15). We also observed that induction of $\mathrm{H}-2^{\mathrm{b} / \mathrm{g} 7}$ or H-2 $2^{\mathrm{s} / \mathrm{g} 7}$ Haplo-MC increased the percentage of Foxp3 $3^{+}$ tTregs among host-type DP and $\mathrm{CD} 4^{+} \mathrm{SP}$ thymocytes in WT NOD mice (Figure 3A) and increased percentage of Foxp3 ${ }^{+}$tTregs among $\mathrm{CD}^{+} \mathrm{SP}$ thymocytes in transgenic BDC2.5 NOD mice (Figure 3B). Foxp $3^{+}$tTregs among DP thymocytes in the mixed chimeric BDC2.5 NOD mice were not measured, since there were too few host-type DP thymocytes for reliable analysis, as shown in Figure 2B. Donor-type Treg production was also enhanced in the thymus of transgenic BDC2.5 NOD mice, although not in the thymus of WT NOD mice (Supplemental Figure 8). These results 
indicate that Haplo-MC augments thymic generation of host-type tTregs in NOD mice.

Donor-type DC subsets are present in the thymus of Haplo-MC mice. There are multiple subsets of CD11 $\mathrm{c}^{+} \mathrm{DCs}$ in the thymus,

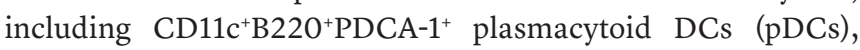
$\mathrm{CD}^{+}{ }^{+} \mathrm{SIRP}^{-}$thymus-resident $\mathrm{DCs}$ (tDCs), and CD8 ${ }^{-} \mathrm{SIRP} \alpha^{+}$ migratory DCs (mDCs). pDCs and tDCs augment thymic negative selection with limited impact in Treg generation; in contrast, $\mathrm{mDCs}$ augment both central negative selection and tTreg generation (34-37). We observed that all 3 subsets of donor-type DCs were present in the thymus of the WT NOD mice with Haplo-MC (Figure 3C). In comparison with control donor mice, there was a significant increase in $\mathrm{CD} 8^{+} \mathrm{tDCs}$, but no difference or a reduction in the percentage of $\mathrm{pDCs}$ and $\mathrm{mDCs}$ (Figure $3 \mathrm{C}$ ). Therefore, the increased negative selection and augmented Treg generation in the thymus of Haplo-MC is associated with presence of donor-type DC subsets.

Haplo-MC augments reduction of host-type CD62L-CD44 ${ }^{\text {hi }}$ effector memory $\mathrm{T}$ cells in the periphery of both euthymic and thymectomized NOD mice. Since $\mathrm{H}-2^{\mathrm{b} / \mathrm{g} 7}$ and $\mathrm{H}-2^{\mathrm{s} / \mathrm{g} 7}$ Haplo-MC eliminated or markedly reduced insulitis in established diabetic NOD mice (Figure 1), we compared the percentage and yield of host-type CD62 $\mathrm{L}^{-} \mathrm{CD} 44^{\mathrm{hi}}$ effector memory (Tem) cells in the spleen, pancreatic lymph nodes (PancLNs), and pancreas of Haplo-MC WT NOD mice. Interestingly, Haplo-MC did not reduce but instead increased the percentage of CD $62 \mathrm{~L}^{-} \mathrm{CD} 44^{\text {hi }} \mathrm{CD} 4^{+}$or $\mathrm{CD} 8^{+}$Tem cells in the spleen, PancLNs, and pancreas of WT NOD mice; however, the yield was markedly reduced (Figure 4, A and B; and Supplemental Figure 10, A and B). We observed similar results in adult-thymectomized NOD mice with Haplo-MC (Supplemental Figure 9).

On the other hand, both percentage and yield of host-type autoreactive CD62L-CD $44^{\text {hi }}{ }^{-}$D $4{ }^{+}$Tem cells in the spleen or PancLNs of Haplo-MC transgenic BDC2.5 NOD mice were markedly reduced (Figure 4C and Supplemental Figure 10C). Furthermore, we used a HIP 2.5 tetramer that specifically identifies chromogranin-proinsulin hybrid peptide-specific autoreactive CD4 ${ }^{+} \mathrm{T}$ cells (38) and an NRP-V7 tetramer that specifically identifies IGRP ${ }_{206-214}$ peptide-specific autoreactive $\mathrm{CD} 8^{+} \mathrm{T}$ cells (39) to measure the changes of the antigen-specific autoreactive Foxp $3^{-} \mathrm{CD} 4^{+}$and $\mathrm{CD}^{+} \mathrm{T}$ cells in the pancreas. Tetramer ${ }^{+} \mathrm{CD} 4^{+}$or $\mathrm{CD} 8^{+} \mathrm{T}$ cells in WT NOD mice given conditioning alone were detectable only in the pancreas but not in the spleen or PancLNs, about $1 \%$ among Foxp $3 \mathrm{CD}^{+} \mathrm{T}$ and about $10 \%$ among $\mathrm{CD}^{+} \mathrm{T}$ cells (Figure $4 \mathrm{D}$ ). Both $\mathrm{H}-2^{\mathrm{b} / \mathrm{g} 7}$ and $\mathrm{H}-2^{\mathrm{s} / \mathrm{g} 7}$ Haplo-MC clearly depleted the autoreactive Foxp3 ${ }^{-} \mathrm{CD}^{+}$or $\mathrm{CD}^{+} \mathrm{T}$ cells in the pancreas of Haplo-MC WT NOD mice (Figure 4D). These results indicate that Haplo-MC preferentially reduces host-type autoreactive Foxp $3^{-}$conventional $\mathrm{T}$ cells in the periphery.

Haplo-MC augments expansion of $N r p 1^{+} C D 73^{h i} F R 4^{h i}$ anergic $C D 4^{+} \mathrm{T}$ cells in the periphery of euthymic but not thymectomized NOD mice. $\mathrm{CD} 73^{\text {hi }} \mathrm{FR} 4{ }^{\text {hi }} \mathrm{CD} 44^{+} \mathrm{T}$ cells in the periphery are anergic T cells (40), and $\mathrm{Nrp}^{+}$anergic $\mathrm{CD} 4^{+} \mathrm{T}$ cells can be the precursors of Helios ${ }^{-} \mathrm{Nrp}^{+}$peripheral Treg (pTreg) cells $(41,42)$. We also found that, compared with control NOD mice, the residual CD $4^{+}$ Tem cells in the PancLNs and pancreas of Haplo-MC NOD mice contained a higher percentage of anergic $\mathrm{CD} 73^{\text {hi }} \mathrm{FR} 4^{\mathrm{hi}} \mathrm{CD} 4^{+} \mathrm{T}$ cells and a higher percentage of $\mathrm{Nrp}^{+}$cells among the $\mathrm{CD} 73^{\mathrm{hi}} \mathrm{FR} 4^{\mathrm{hi}}$
Tem cells (Figure 5, A and B). We also observed that with ThymecNOD mice, the conditioning alone increased the percentage of $\mathrm{CD} 73^{\text {hi }} \mathrm{FR} 4^{\text {hi }}$ cells among residual host-type CD62L-CD $44^{\text {hi }} \mathrm{CD} 4^{+}$ Tem cells in the PancLNs as compared with unconditioned mice, and induction of mixed chimerism did not further increase the percentage (Supplemental Figure 11). Additionally, there was no difference in the percentage of $\mathrm{Nrp}^{+}$cells among the CD73 ${ }^{\text {hi }} \mathrm{FR} 4^{\text {hi }}$ cells in the mixed chimeras (Supplemental Figure 11). These results indicate that residual host-type $\mathrm{CD} 4^{+} \mathrm{T}$ cells in the PancLNs and pancreas of both euthymic and thymectomized Haplo-MC NOD mice have enhanced anergy status, but increase of Nrp1 ${ }^{+}$anergic $\mathrm{CD}^{+} \mathrm{T}$ cells is only observed in euthymic Haplo-MC NOD mice.

Haplo-MC augments expansion of host-type CD62L-CD44hi effector memory tTregs and Helios ${ }^{-N r p 1^{+}}$pTregs in the PancLNs and pancreas of euthymic but not thymectomized NOD mice. Foxp $3^{+}$Tregs in the periphery include thymus-derived $\mathrm{Helios}^{+}$tTregs and peripheral conventional T-derived antigen-specific Helios ${ }^{-N} \mathrm{Nr}^{+}$pTregs (42). tTregs and pTregs play important roles in regulating systemic and local autoimmunity, respectively (43). Changes of Tregs in the spleen reflect systemic, and changes in the organ or organ-draining lymph nodes such as PancLNs and pancreas reflect local, regulation of immune response. Thus, we measured the changes of donorand host-type Treg subsets in the periphery including spleen, PancLNs, and pancreas of Haplo-MC NOD mice. We found that total host-type Tregs were expanded in the PancLNs and pancreas of both $\mathrm{H}-2^{\mathrm{b} / \mathrm{g} 7}$ and $\mathrm{H}-2^{\mathrm{s} / \mathrm{g} 7}$ Haplo-MC mice, although Treg expansion in the spleen was observed only in $\mathrm{H}-2^{\mathrm{b} / \mathrm{g} 7}$ but not in $\mathrm{H}-2^{\mathrm{s} / \mathrm{g} 7}$ mixed chimeras (Figure 6A). Based on Helios and CD62L staining, we observed significant expansion of CD62L-Helios ${ }^{+}$effector memory tTregs in the PancLNs of both mixed chimeras as compared with NOD mice given conditioning alone (Figure 6B).

As mentioned above, we observed expansion of $\mathrm{Nrp}^{+}$ $\mathrm{CD} 73^{\text {hi }} \mathrm{FR} 4^{\text {hi }} \mathrm{CD} 4^{+} \mathrm{T}$ cells, the $\mathrm{Nrp} 1^{+}$pTreg precursors, in HaploMC NOD mice (Figure 5). Thus, we compared the percentage of $\mathrm{Nrp}^{+} \mathrm{Helios}^{-}$pTregs in $\mathrm{H}-2^{\mathrm{b} / \mathrm{g} 7}$ and $\mathrm{H}-2^{\mathrm{s} / \mathrm{g} 7}$ Haplo-MC. Gating on host-type Helios-Foxp $3^{+}$pTregs, we found that there was an increase of $\mathrm{Nrp}^{+}$pTregs in the spleen and PancLNs of $\mathrm{H}-2^{\mathrm{b} / \mathrm{g} 7}$ mixed chimeras and an increase of $\mathrm{Nrp} 1^{+}$pTregs in the pancreas of $\mathrm{H}-2^{\mathrm{s} / \mathrm{g} 7}$ mixed chimeras (Figure 6C). Upregulation of ICOS, GITR, and CTLA-4 expression is associated with enhanced Treg function (44-47), and consistently, host-type Tregs in the PancLNs of mixed chimeras upregulated expression of ICOS and GITR, although no difference in CTLA-4 expression was observed (Supplemental Figure 12). No difference was observed in Treg expression of ICOS, GITR, or CTLA-4 in the spleen of mixed chimeras or control mice (Supplemental Figure 12).

However, compared with Thymec-NOD mice given conditioning alone, Thymec-NOD mice with Haplo-MC did not show a significant difference in the percentage of total Tregs or host-type Nrp1 ${ }^{+}$Helios ${ }^{-}$pTregs, although they showed an increase in the percentage of Helios ${ }^{+} \mathrm{CD} 6 \mathrm{~L}^{-}$effector memory tTregs among total Tregs (Supplemental Figure 13). Taken collectively, these results indicate that (a) Haplo-MC augments activation and expansion of the host-type Helios ${ }^{+}$tTreg subset in the PancLNs and pancreas of NOD mice; and (b) Haplo-MC also augments expansion of Helios ${ }^{-} \mathrm{Nrp}^{+}$pTregs in euthymic but not thymectomized HaploMC NOD mice. 
A
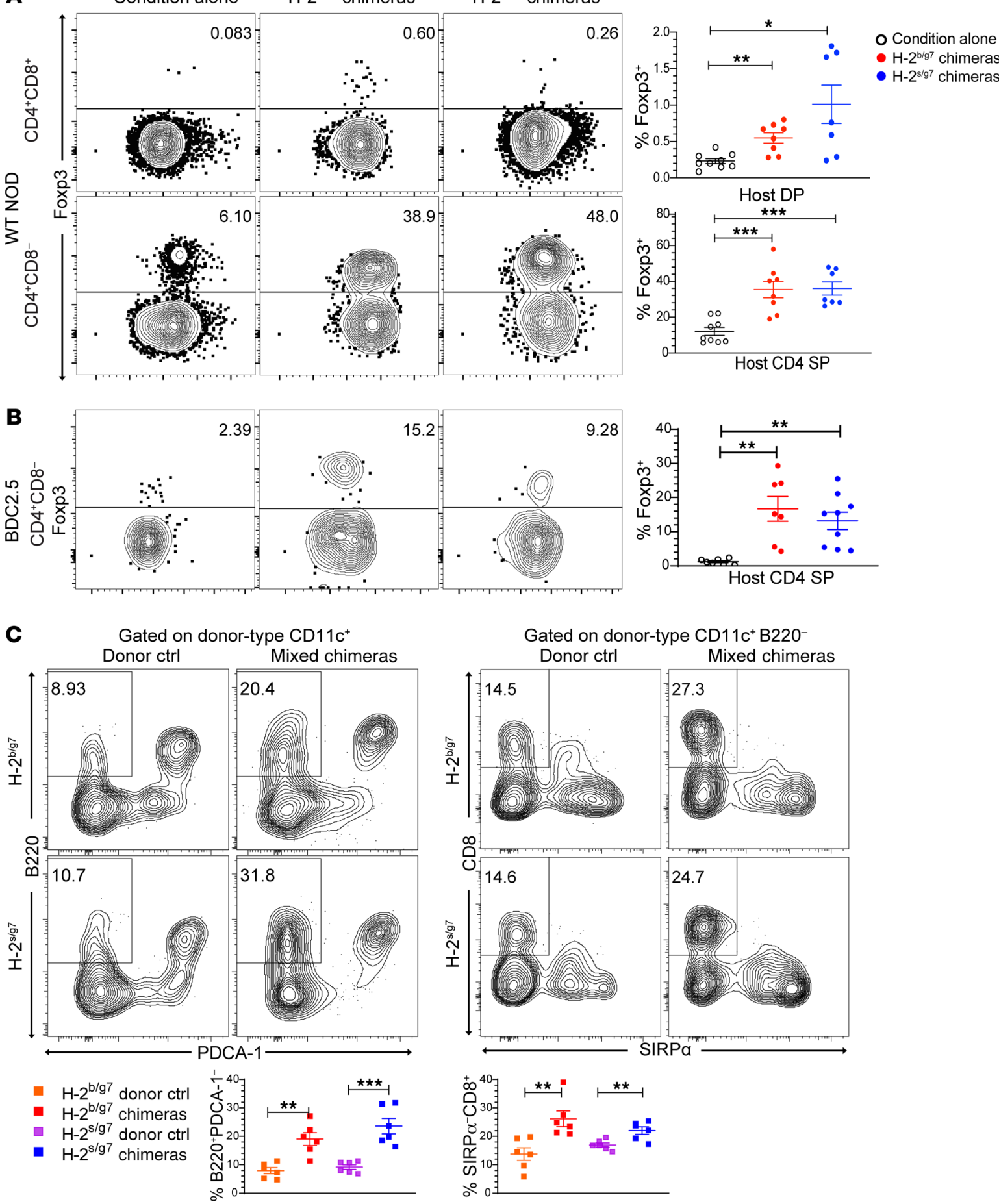

Figure 3. Haplo-MC increases Treg production in thymus, with engraftment of donor-type DC subsets. Sixty days after $\mathrm{HCT}, \mathrm{H}-2^{\mathrm{b} / \mathrm{g} 7}$ and $\mathrm{H}-2^{5 / \mathrm{g} 7} \mathrm{Haplo}-\mathrm{MC}$ and control mice were measured for host-type Foxp3 ${ }^{+}$Tregs among CD4+CD8- (CD4 SP) or CD4+CD8 (DP) thymocytes as well as measured for donor-type DC subsets. (A) Percentage Tregs among host-type CD4+ SP and DP thymocytes in WT NOD ( $n=7-9)$. (B) Percentage Tregs among host-type CD4+ SP thymocytes in BDC2.5 NOD ( $n=7-9)$. (C) Percentage donor-type thymic DC subset among donor-type CD11 ${ }^{+}$DCs, in comparison with healthy donor controls of each strain ( $n=6$ per group). Representative patterns and summary of mean \pm SEM are shown. $P$ values were calculated using unpaired 2-tailed Student's $t$ tests (C) or 1-way ANOVA (A and $\mathbf{B}) ;{ }^{*} P<0.05,{ }^{* *} P<0.01,{ }^{* *} P<0.001$.

Haplo-MC augments expansion of donor-type CD62L-CD44 $4^{\text {hi }}$ effector memory tTregs in the PancLNs and pancreas of euthymic and thymectomized NOD mice. Donor-type Tregs were present in the spleen, PancLNs, and pancreas of both $\mathrm{H}-2^{\mathrm{b} / \mathrm{g} 7}$ and $\mathrm{H}-2^{\mathrm{s} / \mathrm{g} 7} \mathrm{Haplo}-$
MC mice. As compared with control donor mice, the percentage of total Tregs of Haplo-MC was similar in the spleen and variable in the PancLNs and pancreas (Figure 7A). However, the percentage of CD62L-Helios ${ }^{+}$effector memory tTregs in the Haplo- 
A

O Condition alone SPL

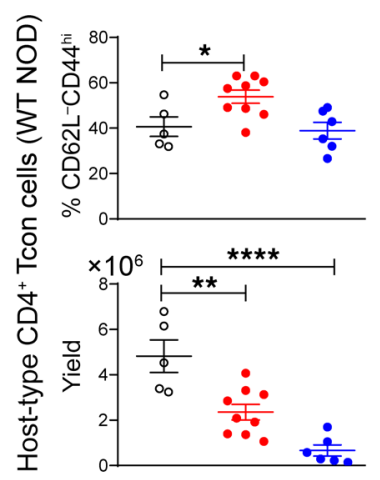

B

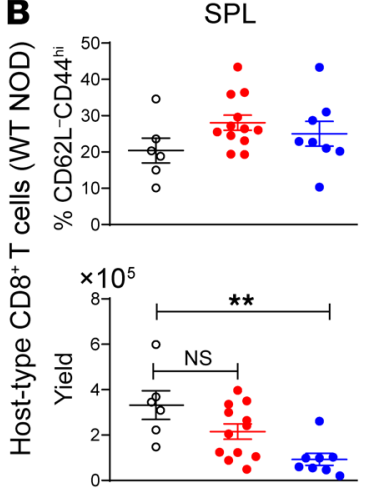

C

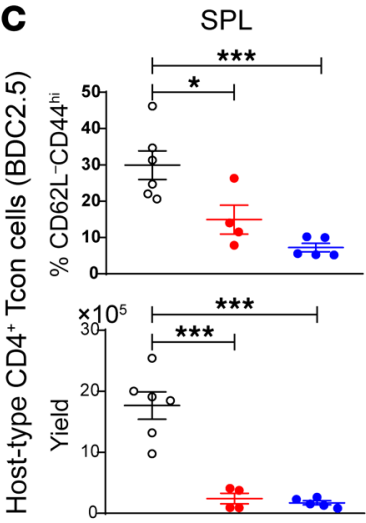

- $\mathrm{H}-2^{\mathrm{b} / \mathrm{g} 7}$ chimeras

PancLN

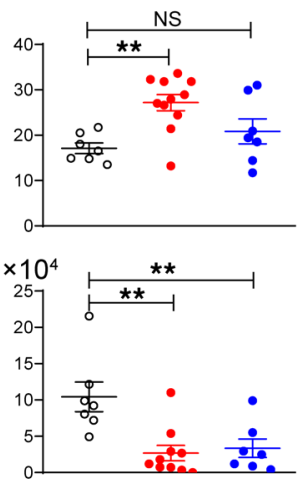

PancLN
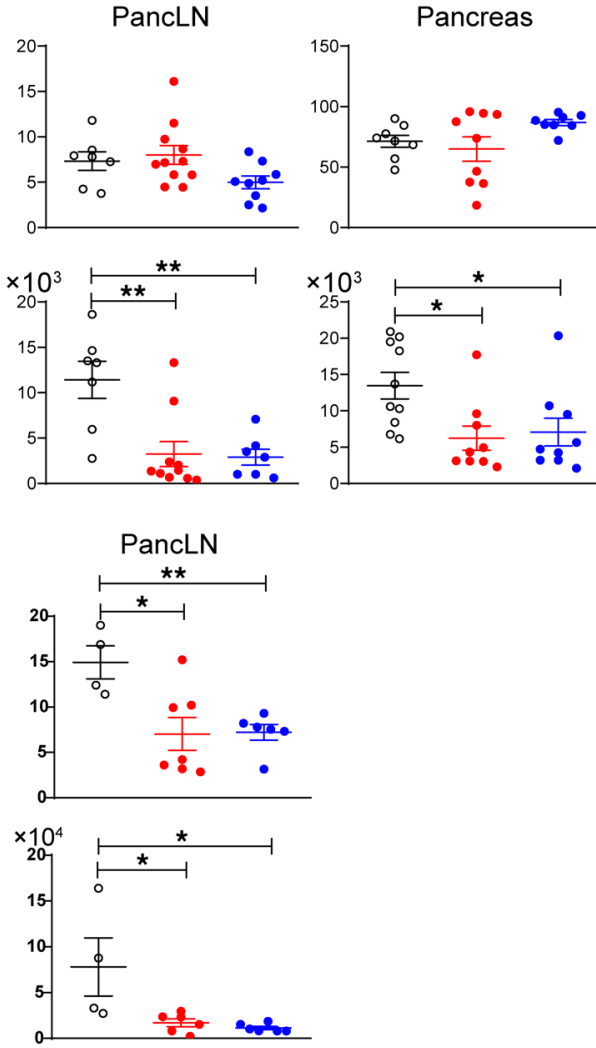

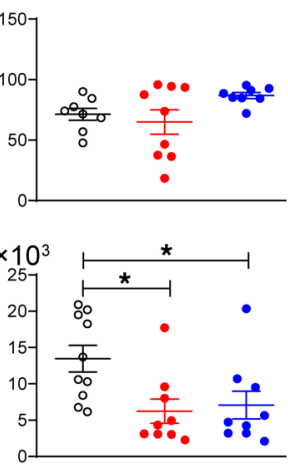

- $\mathrm{H}-2^{\mathrm{s} / 97}$ chimeras Pancreas
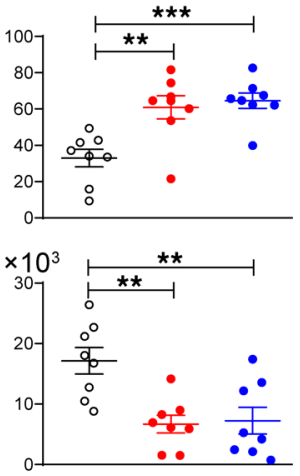

Pancreas
D
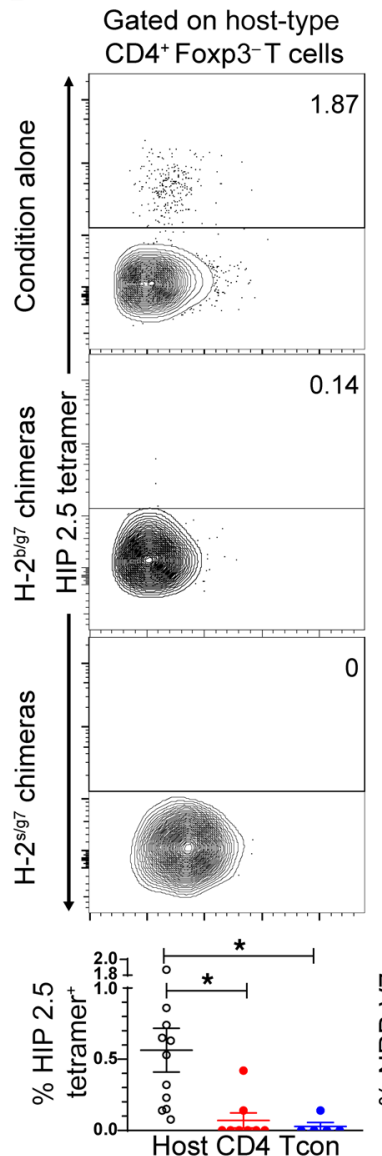

Pancreas

Gated on host-type CD8 ${ }^{+} T$ cells

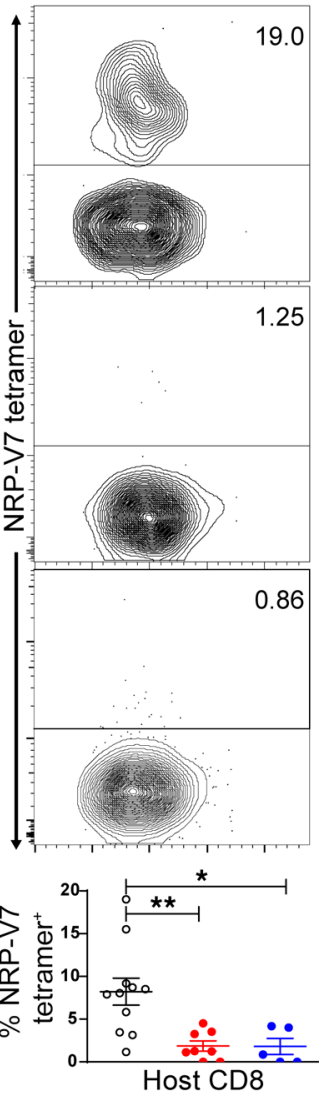

Figure 4. Haplo-MC in NOD mice reduces host-type autoreactive effector memory T cells in the pancreas of WT and BDC2.5 NOD mice. Sixty to 80 days after HCT, mononuclear cells (MNCs) of spleen, PancLNs, and pancreas of mixed chimeric or control WT and BDC2.5 NOD mice were analyzed by flow cytometry for host-type CD44 hiCD62 - ${ }^{-}$CD4+ or CD8+ Tem cells. Mean \pm SEM of percentage and yield of CD62L-CD44 hi Tem cells in the spleen (SPL), pancreatic LNs (PancLNs), and pancreas is shown. (A and B) CD4 ${ }^{+}$and CD8 ${ }^{+}$Tcon cells of WT NOD mice with Haplo-MC or given conditioning alone ( $\left.n=5-12\right)$. (C) Percentage and yield of CD62L-CD44hicD4+ Tem cells in BDC2.5 NOD mice $(n=4-7)$. (D) Percentage of antigen-specific autoreactive T cells in the pancreas of WT NOD mice. The pancreatic MNCs of Haplo-MC or control WT NOD mice were stained with I-A $\mathrm{A}^{\mathrm{g} 7} \mathrm{HIP} 2.5$ tetramer to identify antigen-specific autoreactive $\mathrm{CD}^{+} \mathrm{T}$ cells or $\mathrm{H}-2^{\mathrm{d}} \mathrm{NRP}-\mathrm{V} 7$ tetramer to identify autoreactive CD8 ${ }^{+} \mathrm{T}$ cells. Representative flow cytometry patterns and mean $\pm \mathrm{SEM}$ of percentage of tetramer ${ }^{+} \mathrm{CD}^{+}{ }^{+}$or $\mathrm{CD}^{+} \mathrm{T}$ cells are shown $(n=5-11) . P$ values were calculated using 1-way ANOVA; ${ }^{*} P<0.05,{ }^{* *} P<0.01,{ }^{* * *} P<0.001,{ }^{* * * *} P<0.0001$.

MC mice was increased in both spleen and PancLNs (Figure 7B). Furthermore, donor-type Tregs in the spleen and/or PancLNs of Haplo-MC mice upregulated expression of CTLA-4, although expression of ICOS or GITR was variable (Figure 7C). Similarly, as compared with donor control, there was a marked increase of donor-type total Tregs and Helios ${ }^{+}$CD62L- effector memory tTregs in the PancLNs of Haplo-MC Thymec-NOD mice (Supplemental Figure 14). These results indicate that Haplo-MC augments activation and expansion of donor-type tTregs in the periphery of both euthymic and thymectomized Haplo-MC NOD mice.

Haplo-MC upregulates host-type pDC expression of PD-L1 in euthymic but not thymectomized NOD mice. Peripheral tolerance is associated with tolerogenic DCs, especially pDCs that express high levels of PD-L1 $(48,49)$, and loss of tolerogenic features of pDCs in the periphery plays an important role in T1D pathogenesis $(50,51)$. Thus, we measured changes of host-type DCs as well as their expres- 
A

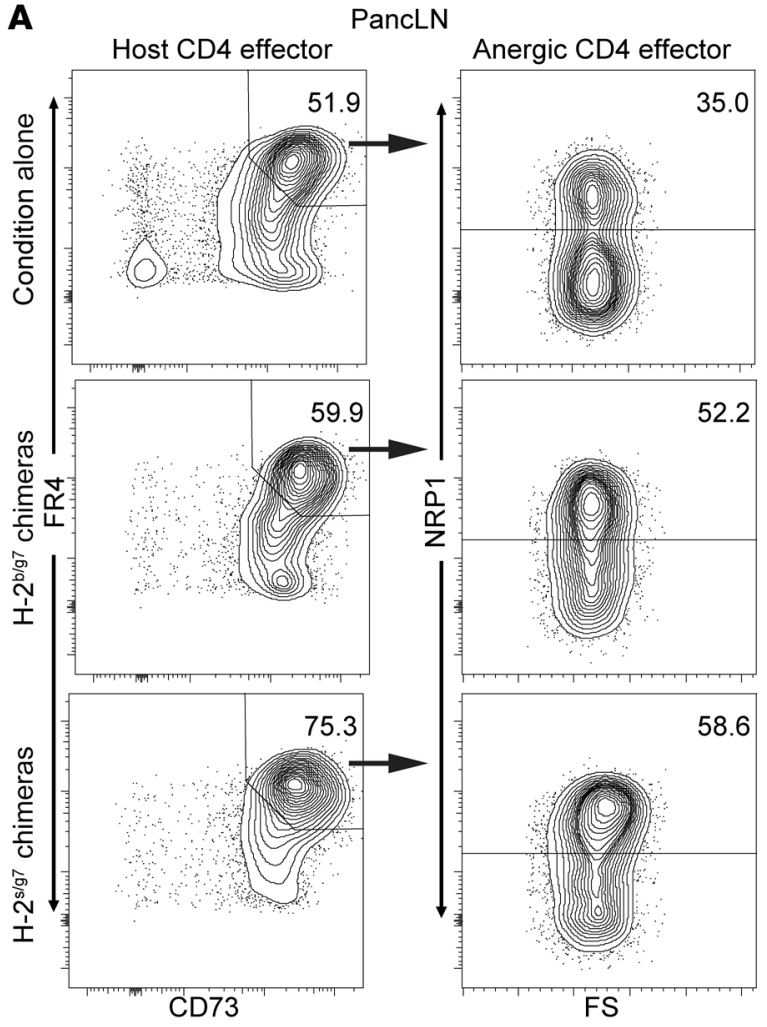

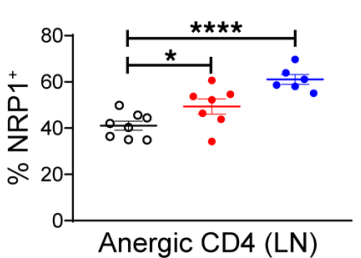

B

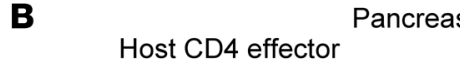

Figure 5. Haplo-MC increases percentage of total CD73 ${ }^{\text {hi } F R 4^{\text {hi }}}$ anergic CD4 ${ }^{+} T$ cells and Nrp1+CD73 ${ }^{\text {hiFR4 }} 4^{\text {hi }}$ anergic cells among host-type CD44 ${ }^{\text {hic }}$ ab62L-CD4 Tem cells. Sixty to 80 days after HCT, samples of PancLNs and pancreas MNCs were analyzed by flow cytometry for their expression of CD45.2 (donor marker), TCR $\beta$, CD4, Foxp3, CD62L, CD44, CD73, FR4, and Nrp1. Representative patterns of flow cytometry and mean \pm SEM of percentage of CD73 ${ }^{\text {hiFR4 }}{ }^{\text {hi }}$ anergic cells among total host-type Foxp $3^{-}$CD62L ${ }^{-}$CD $44^{\text {hi }} C D 4^{+}$Tem cells and percentage of Nrp1 ${ }^{+} C D 73^{\text {hi }} F R 4^{\text {hi }}$ cells among total CD73 $3^{\text {hi }}$ FR $4^{\text {hi }}$ anergic cells are shown $(n=4-8)$. $P$ values were calculated using 1-way ANOVA; ${ }^{*} P<0.05,{ }^{* *} P<0.01,{ }^{* * *} P<0.001,{ }^{* * *} P<0.0001$.

sion of PD-L1 in the spleen of mixed chimeras. We observed that among host-type DCs in both $\mathrm{H}-2^{\mathrm{b} / \mathrm{g}^{7}}$ and $\mathrm{H}-2^{\mathrm{s} / \mathrm{g}^{7}}$ Haplo-MC mice, there was a marked reduction in the percentage of $\mathrm{CD} 11 \mathrm{c}^{+} \mathrm{B} 22 \mathrm{O}^{+}$ PDCA $-1^{+}$pDCs among total host-type DCs, especially in the $\mathrm{H}-2^{5 / g 7}$ mixed chimeras, as compared with that of control mice given conditioning alone, although we observed no significant changes in the percentage of $\mathrm{CD} 8^{+}$or $\mathrm{CD} 11 \mathrm{~b}^{+} \mathrm{DC}$ subsets (Figure $8 \mathrm{~A}$ ). In contrast, the residual pDCs in both mixed chimeras upregulated expression of PD-L1, as did the CD8 ${ }^{+}$DC subset, but not the CD11b ${ }^{+}$DC subset (Figure 8B). Interestingly, although there was a marked reduction of pDCs in the spleen of Haplo-MC Thymec-NOD mice, the residual pDCs did not upregulate their expression of PD-L1 as compared with conditioning alone (Supplemental Figure 15). These results indicate that induction of Haplo-MC reduces host-type pDCs in both euthymic and thymectomized NOD mice, but Haplo-MC augments the residual pDCs to upregulate their expression of PD-L1 in the euthymic but not the thymectomized mice.

Maintenance of peripheral tolerance of residual host-type autoreactive $T$ cells in euthymic Haplo-MC mice requires both donor- and host-type Foxp $3^{+}$Tregs. Since there was an expansion of donor- and host-type effector memory Tregs in both $\mathrm{H}-2^{\mathrm{b} / \mathrm{g}^{7}}$ and $\mathrm{H}-2^{\mathrm{s} / \mathrm{g} 7}$ mixed chimeric NOD mice (Figures 6 and 7), we tested whether those Tregs were required for maintenance of peripheral tolerance by using Foxp $3^{\text {DTR }}$ expression in either donor- or host-type Tregs in $\mathrm{H}-2^{\mathrm{b} / \mathrm{g} 7}$ mixed chimeric NOD mice, as depicted in Figure 9A. Depletion of Tregs was induced by injection of diphtheria toxin (DT) every 3 days for 21 days, starting at 45-60 days after induction of mixed chimerism, as described in Methods. Injection of DT specifically reduced donor-type Tregs by about $95 \%$ and reduced host-type Tregs by about 90\% (Figure 9B and Supplemental Figure 16). Depletion of donor-type or host-type Tregs induced significant but moderate recurrence of insulitis, without causing hyperglycemia (Figure 9C). Simultaneous depletion of both donor- and host-type Tregs did not appear to significantly enhance the insulitis, but because the treatment led to rapid decline of health and the mice died or became very sick without hyperglycemia before completion of treatment, the results could not be used for comparison. Therefore, we focused on comparing depletion of donor- 
A

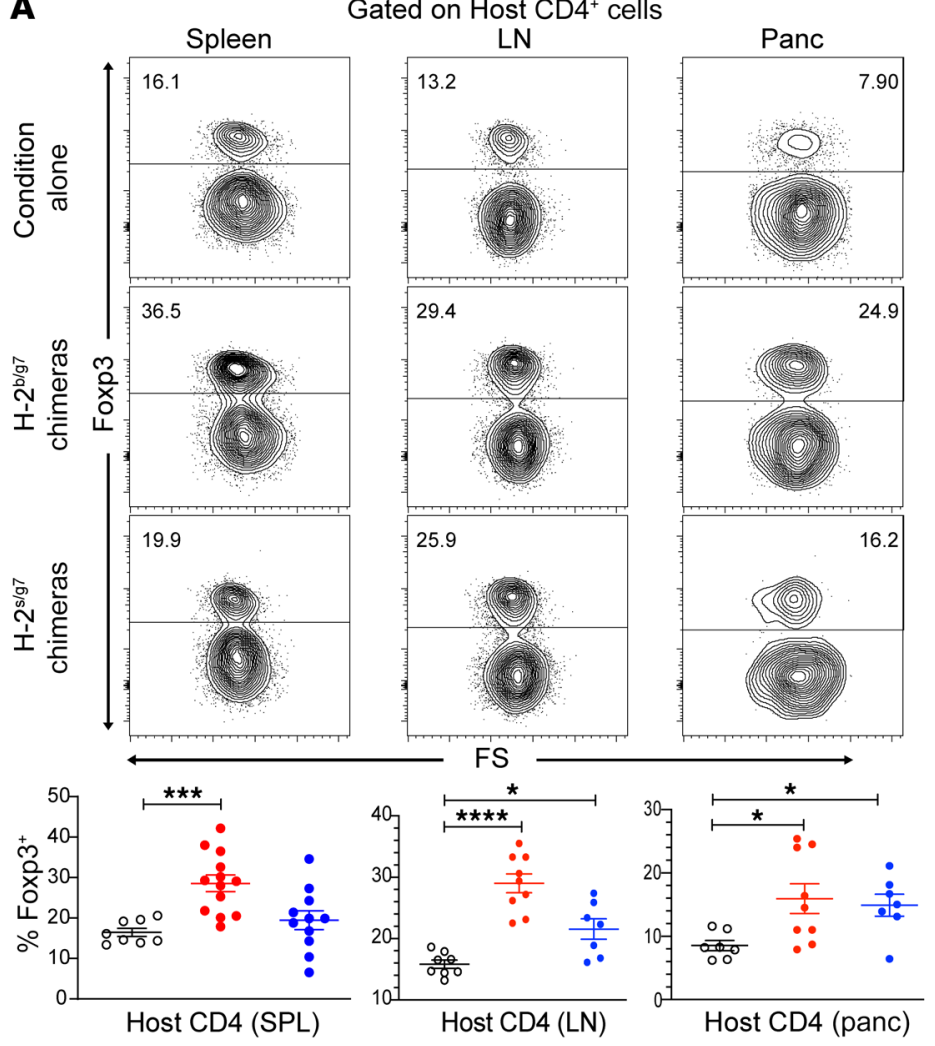

B
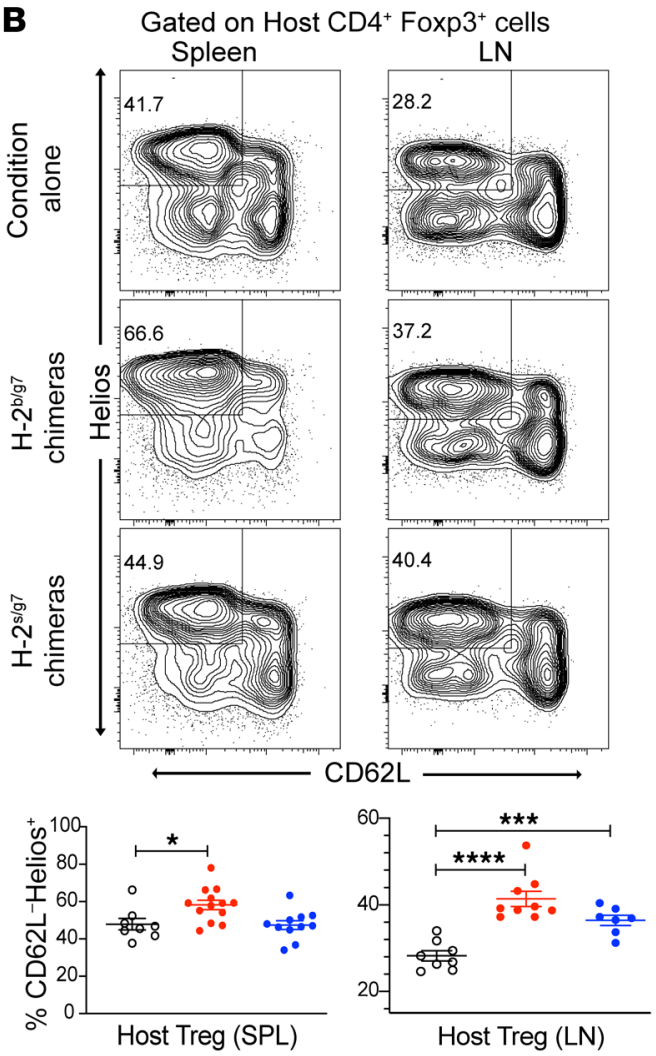

C

Gated on host CD4 ${ }^{+}$Foxp $^{+}$Helios $^{-}$cells
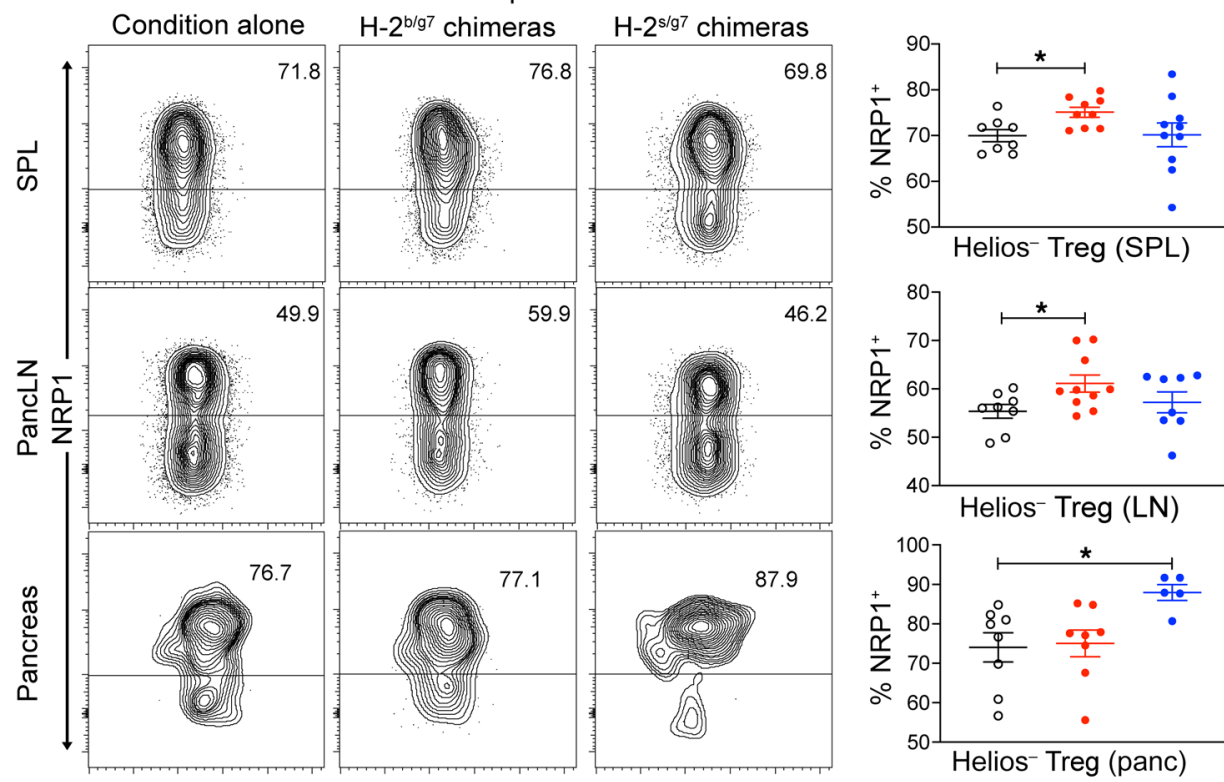

Figure 6. Haplo-MC increases CD62L-Helios+ effector memory Tregs and Nrp1+Helios` pTregs. MNCs from spleen (SPL), PancLNs, and pancreas of HaploMC NOD mice were analyzed at day 60 after HCT for CD62L-Helios ${ }^{+}$effector memory Tregs and Helios ${ }^{-N r p 1^{+}}$pTregs. (A) Representative patterns and mean \pm SEM of Foxp3 $3^{+}$Tregs among total host-type CD4+ T cells $(n=7-13)$. (B) Representative patterns and mean \pm SEM of percentage of CD62L-Helios ${ }^{+}$effector memory Tregs among total Foxp $3^{+} \mathrm{CD} 4^{+}$Tregs in the spleen, PancLNs, and pancreas $(n=7-13)$. (C) Representative patterns and mean \pm SEM of percentage of $\mathrm{Nrp1}^{+}$pTregs among host-type Helios ${ }^{-}$TTregs in spleen, PancLNs, and pancreas $(n=5-10)$. $P$ values were calculated using 1 -way ANOVA; ${ }^{*} P<0.05$, ${ }^{* * *} P<0.001,{ }^{* * * *} P<0.0001$.

type versus depletion of host-type Tregs. Depletion of donor-type Tregs but not depletion of host-type Tregs led to an increase in the percentage of host-type $\mathrm{CD} 4^{+}$and $\mathrm{CD} 8^{+} \mathrm{CD} 62 \mathrm{~L}^{-} \mathrm{CD} 44^{+}$effector memory conventional T cells (Tcon cells) in the PancLNs (Figure
9D); in contrast, depletion of host-type but not donor-type Tregs led to a decrease in the percentage of $\mathrm{CD} 73^{\mathrm{hi}} \mathrm{FR} 4^{\mathrm{hi}}$ anergic $\mathrm{CD} 4^{+}$ Tcon and IL-7R $\alpha$ PD- $1^{\text {hi }}$ anergic/exhausted CD $8^{+}$Tcon cells (Figure 9E). These results indicate that both donor- and host-type Tregs 
A

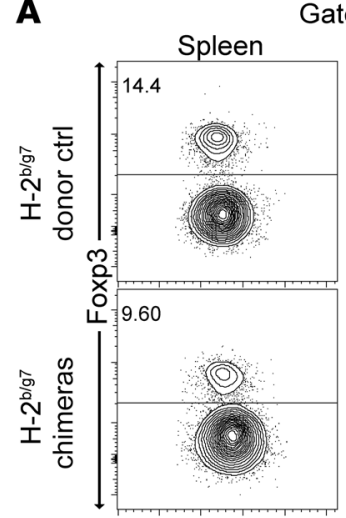

Gated on donor $\mathrm{CD} 4^{+} \mathrm{T}$ cells
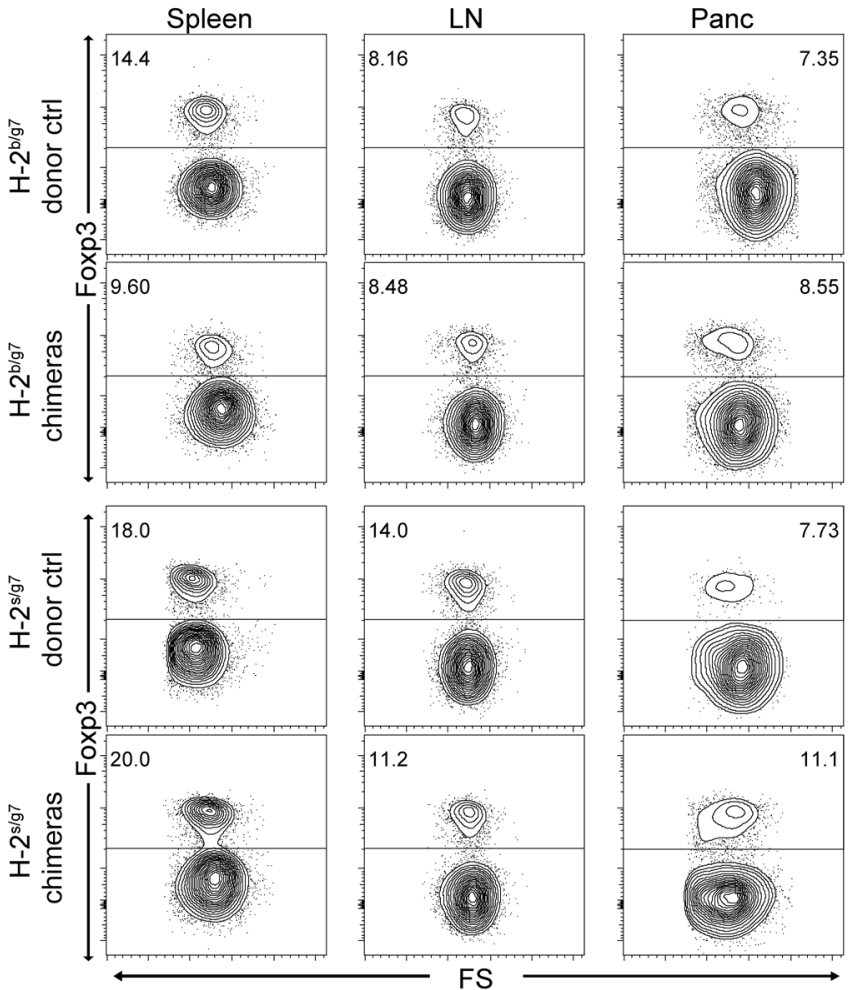

$\square \mathrm{H}-2^{\mathrm{b} / \mathrm{g} 7}$ donor

$\square \mathrm{H}-2^{\mathrm{s} / \mathrm{g} 7}$ donor

$\mathrm{H}-2^{\mathrm{b} / \mathrm{g} 7}$ chimeras

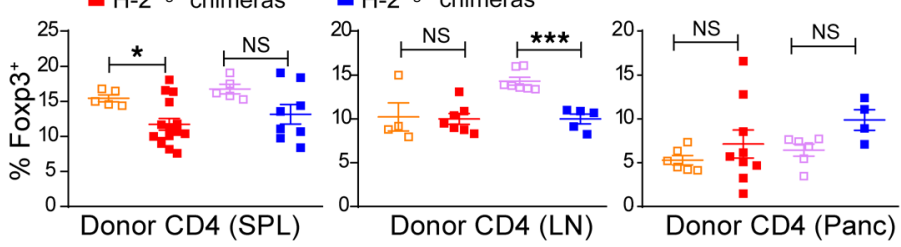

B Gated on donor CD4 ${ }^{+} \mathrm{T}$ cells
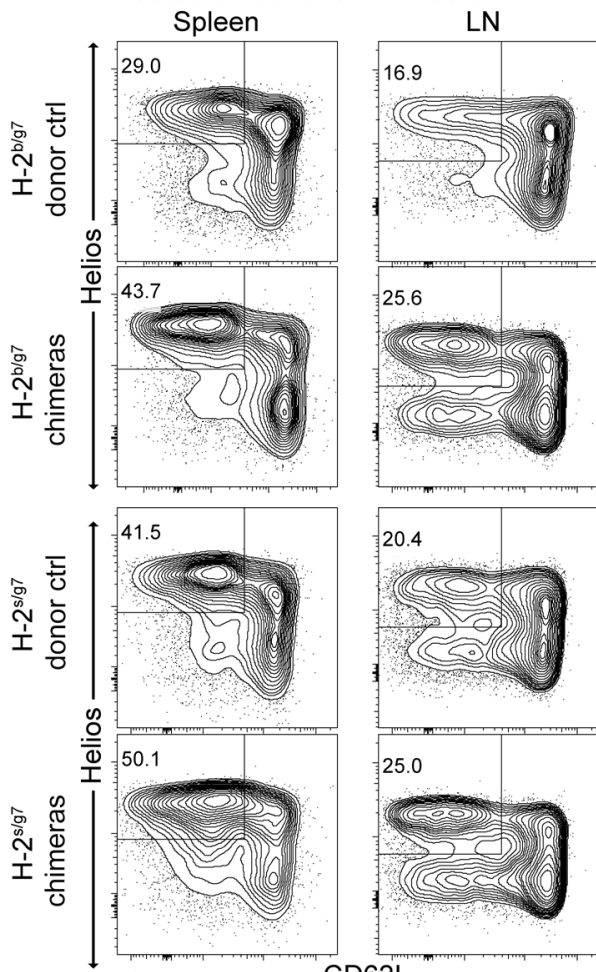

CD62L
C
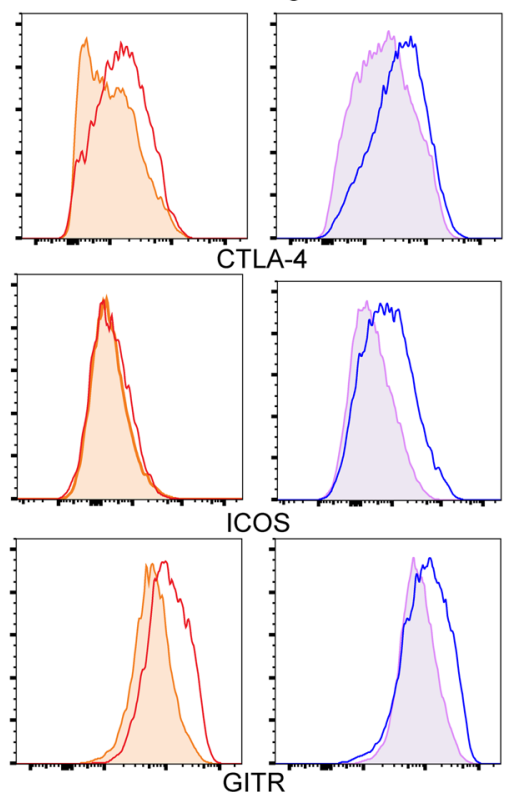
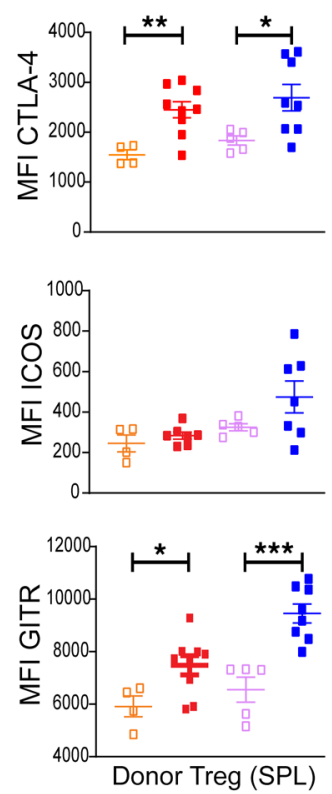

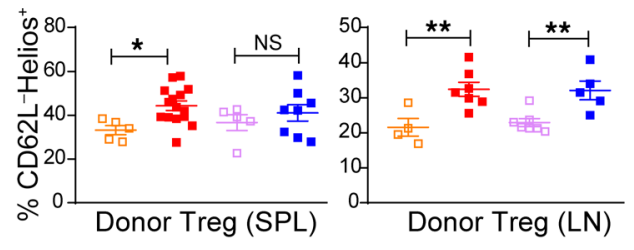

Donor Treg-LN
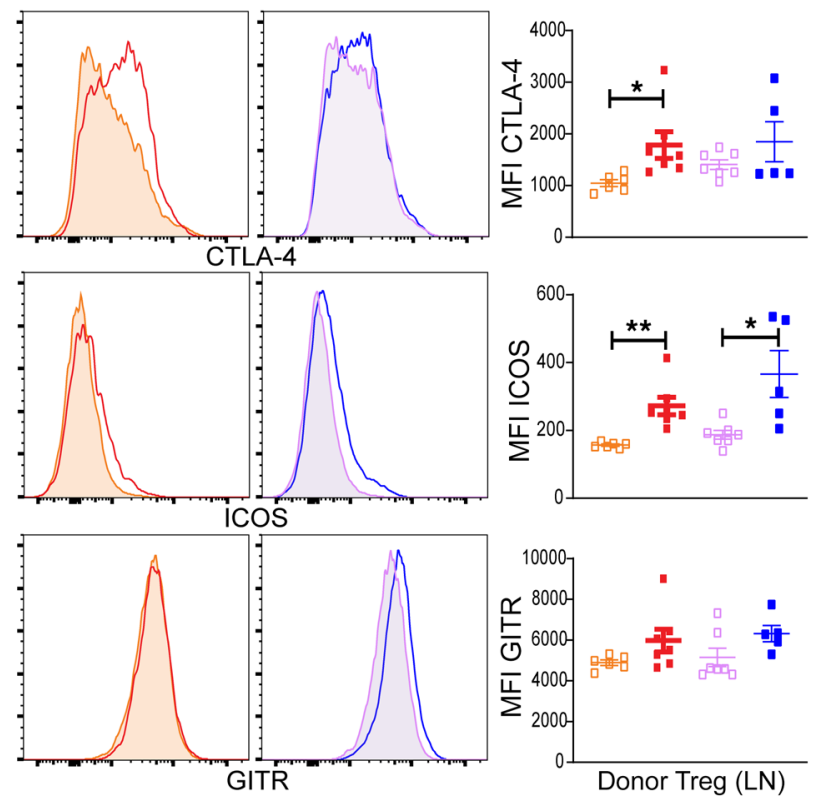
Figure 7. Haplo-MC increases percentage of donor-type CD62L- effector memory Tregs and upregulates their CTLA-4 expression. Sixty days after HCT, cells from spleen (SPL), PancLNs, and pancreas of Haplo-MC NOD and control donor mice were analyzed for percentage of donor-type Tregs among total donor-type CD4+ $T$ cells and percentage of CD62L- effector memory Tregs among total donor-type Foxp3 ${ }^{+} \mathrm{CD} 4^{+}$Tregs as well as Treg expression of CTLA-4, ICOS, and GITR. (A and B) Representative patterns and mean \pm SEM show percentage of Tregs among donor-type CD4 ${ }^{+} \mathrm{T}$ cells or CD62L-Helios ${ }^{+}$effector memory Tregs among donor-type Tregs $(n=6-11)$. (C) Representative patterns and mean \pm SEM of median fluorescence intensity (MFI) of CTLA-4, ICOS, and GITR expressed by donor-type Tregs in spleen and PancLNs $(n=4-9)$. $P$ values were calculated using unpaired 2-tailed Student's $t$ tests; ${ }^{*} P<0.05,{ }^{* *} P<0.01,{ }^{* *} P<0.001$.

contribute to maintenance of peripheral tolerance of residual autoreactive $\mathrm{T}$ cells, although each have a different functional effect.

Maintenance of peripheral tolerance of residual host-type autoreactive $T$ cells requires host hematopoietic cell expression of PD-L1. Because host-type DCs, especially pDCs, in the $\mathrm{H}-2^{\mathrm{b} / \mathrm{g} 7}$ and $\mathrm{H}-2^{5 / \mathrm{g}^{7}}$ Haplo-MC euthymic NOD mice expressed higher levels of PD-L1 as compared with mice given conditioning alone (Figure 8), we tested whether host DC expression of PD-L1 was required for maintenance of peripheral tolerance using $\mathrm{H}-2^{\mathrm{b} / \mathrm{g} 7}$ mixed chimeric NOD mice. Parenchymal cell expression of PD-L1 was reported to play a critical role in prevention of T1D in NOD mice (52). We wished to evaluate the role of host-type DC expression of PD-L1 in maintaining peripheral tolerance in the presence of host parenchymal tissue expression of PD-L1. Accordingly, we established Haplo-MC by coinjection of donor-type TCD-BM from $\mathrm{H}-2^{\mathrm{b} / \mathrm{g}^{7}} \mathrm{~F}_{1}$ donor mice and host-type TCD-BM from WT or PD-L1 ${ }^{-/-}$NOD mice into lethally irradiated WT NOD mice, as depicted in Figure 10A. The control NOD recipients were given PD-L1 $1^{-/}$NOD TCD-BM alone.

The NOD recipients with TCD-BM from $\mathrm{H}-2^{\mathrm{b} / \mathrm{g} 7} \mathrm{~F}_{1}$ donor and TCD-BM from syngeneic WT or PD-L1 $/-$ NOD mice developed stable mixed chimerism (Supplemental Figure 17). While none (0/12) of the $\mathrm{H}-2^{\mathrm{b} / \mathrm{g} 7}$ mixed chimeras that received PD-L1 ${ }^{+/+}$NOD TCDBM (PD-L1 ${ }^{+/+}$chimeras) developed T1D or hyperglycemia, $82 \%$ (9/11) of the $\mathrm{H}-2^{\mathrm{b} / \mathrm{g} 7}$ mixed chimeras that received $\mathrm{PD}-\mathrm{L1}^{-/} \mathrm{NOD}$ TCD-BM (PD-L1-/ chimeras) developed T1D with hyperglycemia, and $94 \%(17 / 18)$ of NOD recipients given PD-L1 $1^{-/-}$NOD TCD-BM alone (PD-L1 ${ }^{--}$NOD) developed T1D with hyperglycemia (Figure 10B). Furthermore, as compared with PD-L1 ${ }^{+/+}$mixed chimeras without T1D, PD-L1 ${ }^{-/-}$mixed chimeras with T1D showed expansion of host-type $\mathrm{CD} 4^{+}$and $\mathrm{CD} 8^{+}$effector $\mathrm{T}$ cells in the PancLNs and pancreas (Figure 10C). Those effector $\mathrm{T}$ cells had a decrease in the percentage of anergic CD7 $3^{\text {hi }} \mathrm{FR} 4^{\mathrm{hi}} \mathrm{CD} 4^{+} \mathrm{T}$ cells (Figure 10D). These results indicate that host-type hematopoietic cell expression of PD-L1 is required for maintenance of peripheral tolerance of residual autoreactive T cells in Haplo-MC euthymic NOD mice.

There is a mutual influence and compensatory role between donor- and host-type Tregs in euthymic Haplo-MC NOD mice. Both donor- and host-type Tregs were activated in the Haplo-MC NOD mice, as indicated by the relative increase of $\mathrm{CD} 62 \mathrm{~L}^{-}$effector memory Tregs, although they showed different changes in surface receptors: donor-type Tregs upregulated expression of CTLA-4, but host-type Tregs upregulated expression of ICOS and GITR (Figures 6 and 7 and Supplemental Figure 12). Next, we evaluated whether there was a mutual influence between donor- and host- type Tregs in the Haplo-MC NOD mice. Depletion of donor-type Tregs led to a slight increase in the percentage of host-type Tregs and a significant upregulation of expression of CTLA-4 in the spleen and PancLNs (Figure 11, A and B). However, upregulation of expression of ICOS and GITR was observed only in the spleen but not in the PancLNs (Figure 11B). In contrast, depletion of hosttype Tregs led to significant expansion of donor-type Tregs and their upregulation of expression of CTLA-4 in the spleen but not in the PancLNs. In addition, no significant changes in ICOS and GITR expression were observed in the spleen or PancLNs (Figure $11, C$ and D). These results suggest that the regulatory emphasis of donor- and host-type Tregs differs: donor-type Tregs are more involved in regulating systemic immune response such as in the spleen, and host-type Tregs are more involved in regulating local immune response such as in the PancLNs. These observations may also provide an explanation why depletion of donor- or hosttype Tregs alone did not cause overt insulitis or hyperglycemia in the Haplo-MC NOD mice.

Donor-and host-type tTregs are required for upregulation of hosttype pDC expression of PD-L1 that augments expansion of host-type and donor-type Nrp1 $1^{+} H e l i o s^{-}$pTregs. Because host-type pDCs were found to upregulate expression of PD-L1 in Haplo-MC euthymic NOD mice (Figure 8), we analyzed the impact of depletion of Tregs on the host-type pDC expression of PD-L1. Interestingly, depletion of either donor-type or host-type Tregs led to a decrease in the percentage of host-type $\mathrm{B} 22 \mathrm{O}^{+} \mathrm{PDCA}-1^{+}$pDCs (Figure 12A) as well as their downregulation of expression of PD-L1 (Figure 12B). These results suggest that donor- and host-type Tregs can augment expansion of host-type pDCs and their expression of PD-L1.

Furthermore, we evaluated the impact of PD-L1 expression by host-type hematopoietic cells on expansion of host-type pDCs and Tregs. We found that PD-L1 deficiency in host-type hematopoietic cells led to a marked decrease in the percentage of hosttype pDCs (Figure 12C), although no reduction in $\mathrm{CD}^{+}$lymphoid or $\mathrm{CD}_{11 \mathrm{~b}^{+}}$myeloid DC subsets (Figure 12D). We also observed that PD-L1 deficiency in host-type hematopoietic cells resulted in no changes in the total percentage of host- and donor-type Foxp $^{+}$Tregs in the spleen, PancLNs, or pancreas (Supplemental Figure 18, A and B). However, the PD-L1 deficiency in host-type hematopoietic cells resulted in a marked reduction in the percentage of host-type Helios ${ }^{-}$pTregs that were predominantly $\mathrm{Nrp}^{+}$in the PancLNs and pancreas as well as marked reduction of donortype Helios ${ }^{-}$Tregs in the pancreas (Figure 12E). Additionally, we observed that expansion of antigen-specific Tregs in the pancreas of Haplo-MC BDC2.5 NOD mice was associated with effective prevention of T1D (Supplemental Figure 19). These results indicate that (a) host-type pDC expression of PD-L1 plays a critical role in expansion of host-type Helios ${ }^{-} \mathrm{Nrp}^{+}{ }^{+}$pTregs in the PancLNs and pancreas of Haplo-MC euthymic NOD mice; and (b) autoantigen-specific pTregs may play an important role in controlling residual autoreactive T cells in Haplo-MC euthymic NOD mice.

\section{Discussion}

Autoimmune T1D is associated with particular MHC (HLA) in mice and humans $(53,54)$ and arises from defects in both central and peripheral tolerance mechanisms (55). We previously reported that induction of full MHC-mismatched but not MHC-matched 


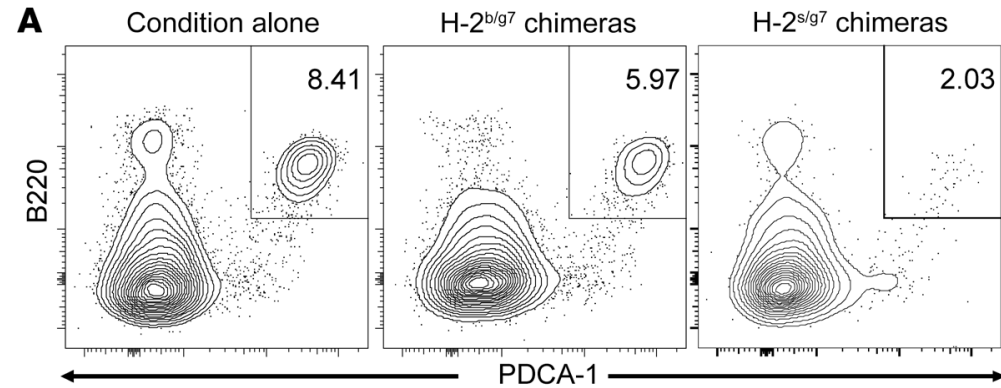

03

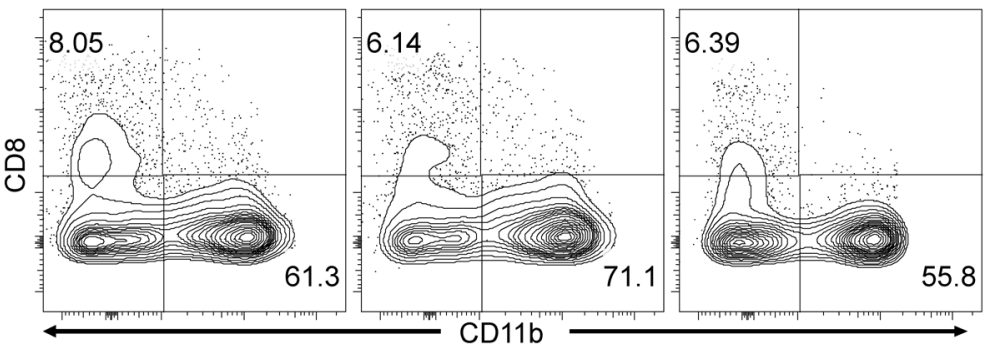

55.8

B
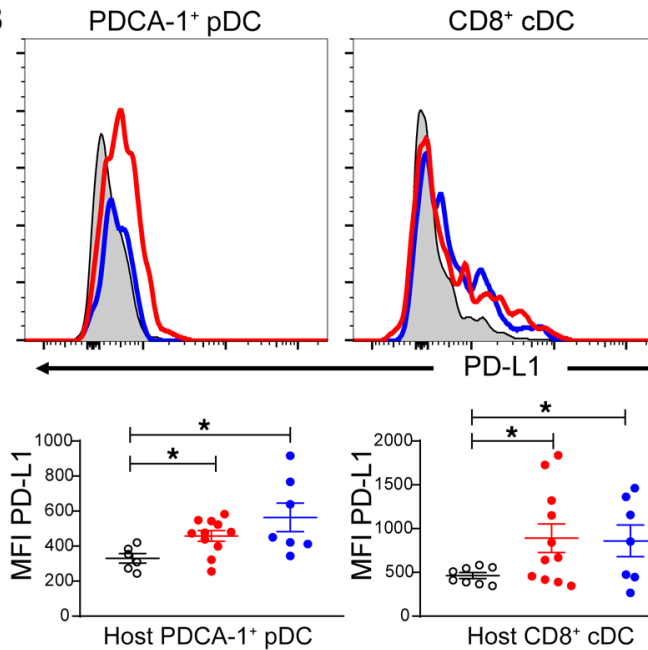

$\mathrm{CD}_{11 \mathrm{~b}^{+} \mathrm{cDC}}$
- Condition alone

- $\mathrm{H}-2^{b / 97}$ chimeras

$\bullet \mathrm{H}-2^{5 / 97}$ chimeras
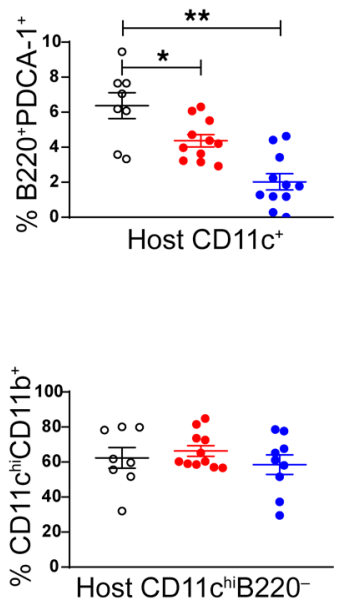

Figure 8. Haplo-MC reduces percentage of host-type PDCs but upregulates their PD-L1 expression. MNCs from spleen of mixed chimeras and control

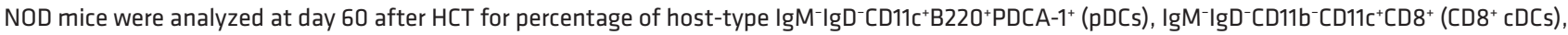
and IgM-IgD-CD11 $\mathrm{b}^{+} \mathrm{CD} 11 \mathrm{C}^{+}\left(\mathrm{CD} 11 \mathrm{~b}^{+} \mathrm{CDCS}\right)$ subsets and their expression of PD-L1. (A) Representative patterns and mean \pm SEM of percentage of host-type B220+PDCA-1+ $1^{+}$DC, CD8 ${ }^{+}$DC, and CD11 b+ DC subsets $(n=8-11)$. (B) Representative patterns and mean \pm SEM of PD-L1 expression levels on host-type $B 220^{+}$PDCA-1 ${ }^{+}$pDCs, B220-CD11b-CD8 ${ }^{+}$DCs, and B220-CD8-CD11 b ${ }^{+}$DCs, in comparison with control mice $(n=6-11)$. $P$ values were calculated using 1-way ANOVA; ${ }^{*} P<0.05,{ }^{* *} P<0.01$.

mixed chimerism was able to reverse autoimmunity in prediabetic, new-onset diabetic, and late-stage diabetic WT NOD mice (18-20); full MHC-mismatched but not matched mixed chimerism augmented thymic negative selection of autoreactive $\mathrm{T}$ cells and tolerized residual autoreactive $\mathrm{T}$ cells in the periphery of BDC2.5 NOD mice with transgenic autoreactive T cells $(6,51)$. However, full MHC-mismatched mixed chimerism is not yet applicable in the clinic. Although haploidentical HCT is now widely used in the clinic (1), whether haploidentical mixed chimerism (Haplo-MC) could cure autoimmunity remains unknown, because MHC (HLA)matched mixed chimerism cannot reverse autoimmunity in mice or humans $(6,7)$. Although we have reported that full MHC-mismatched mixed chimerism can reverse autoimmunity in WT NOD mice and augment thymic negative selection and peripheral toler- ance of autoreactive $\mathrm{T}$ cells in transgenic BDC2.5 NOD mice, the cellular mechanisms of tolerance and how tTregs regulate peripheral DCs and pTregs in the mixed chimera remain unclear.

In the current studies, we have demonstrated that, with a conditioning regimen of ATG $+\mathrm{CY}+\mathrm{PT}$ and depletion of $\mathrm{CD} 4^{+}$ $\mathrm{T}$ cells in the transplant, induction of Haplo-MC effectively cures the established autoimmunity with elimination of insulitis in both euthymic and adult-thymectomized NOD mice, with not only $\mathrm{H}-2^{\mathrm{b} / \mathrm{g}^{7}} \mathrm{~F}_{1}$ donors that possess autoimmune-resistant $\mathrm{H}-2^{\mathrm{b}}$ but also $\mathrm{H}-2^{\mathrm{s} / \mathrm{g} 7}$ donors that possess autoimmune-susceptible $\mathrm{H}-2^{\mathrm{s}}$. The cure of autoimmunity in thymectomized NOD mice is associated with expansion of donor- and host-type Tregs and anergy of residual host-type T cells. The cure of autoimmunity in euthymic NOD mice is associated with preferential augmentation of negative 
A
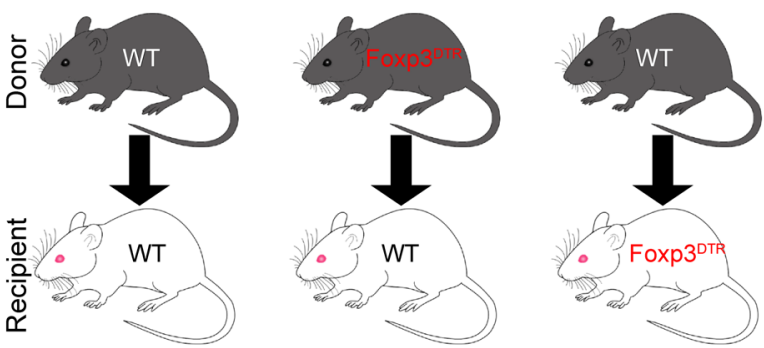

B

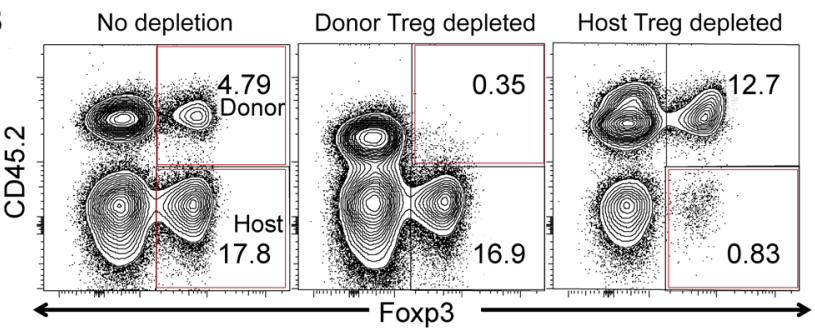

D

Gated on host T cells in PancLN

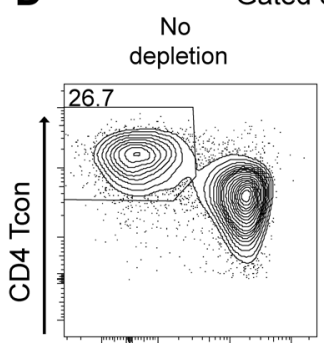
Donor Treg
depleted
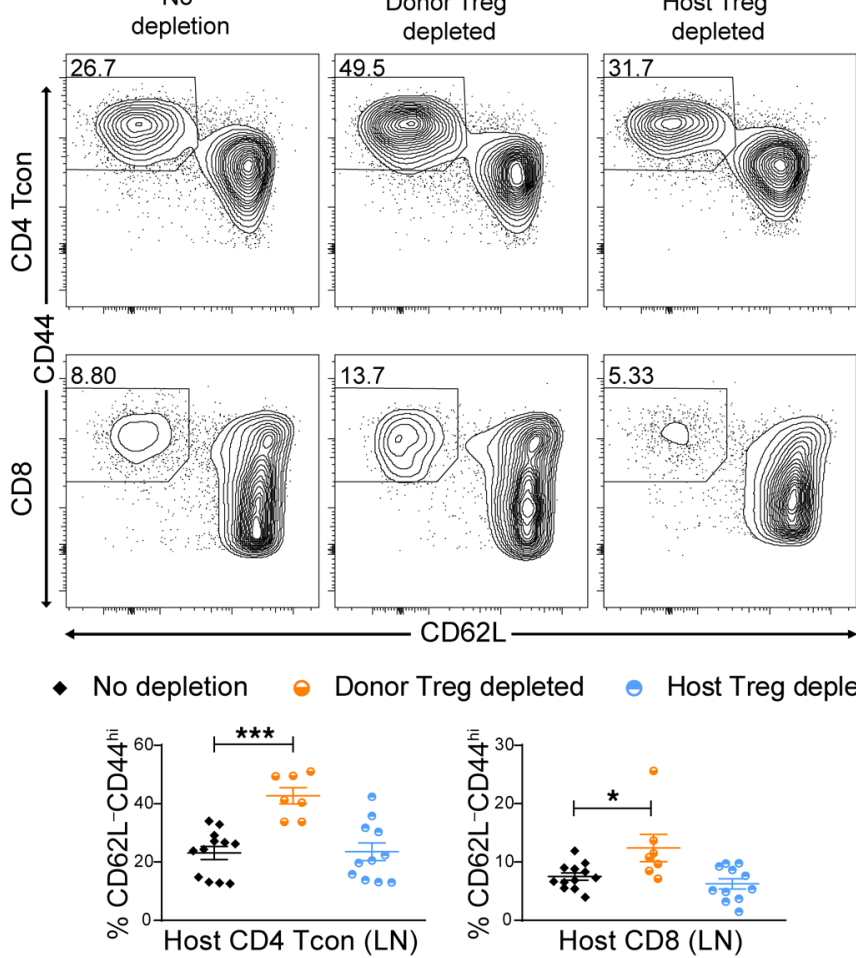

C
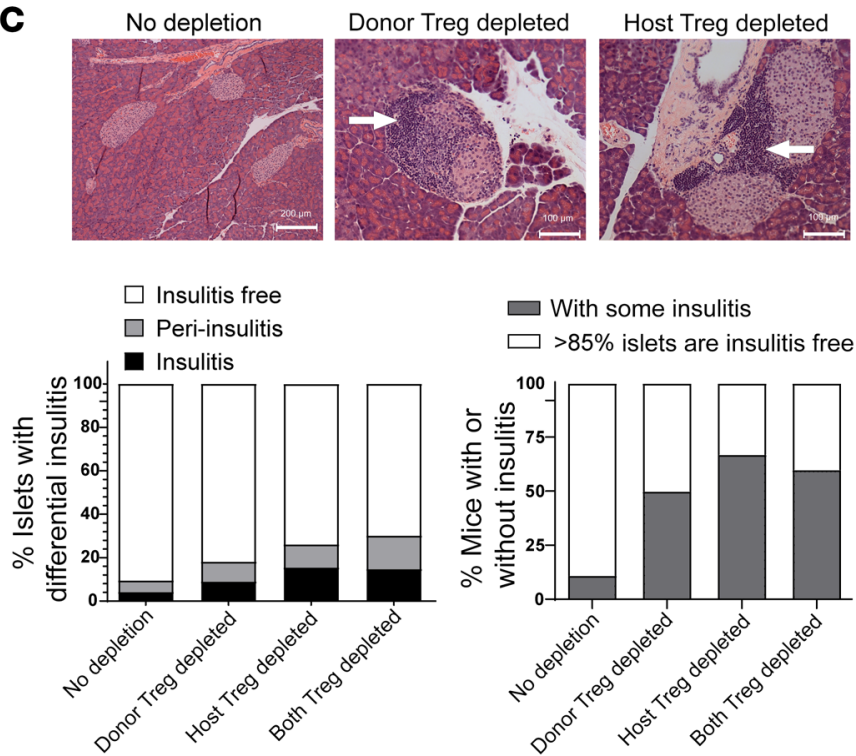

$\square$ With some insulitis

$\square>85 \%$ islets are insulitis free

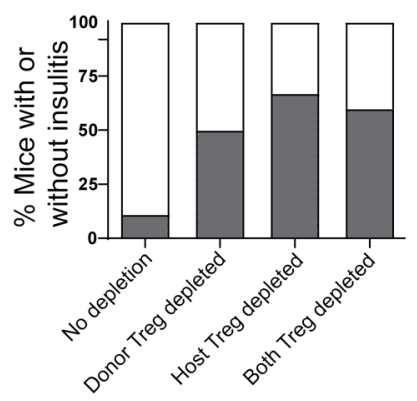

$\mathbf{E}$
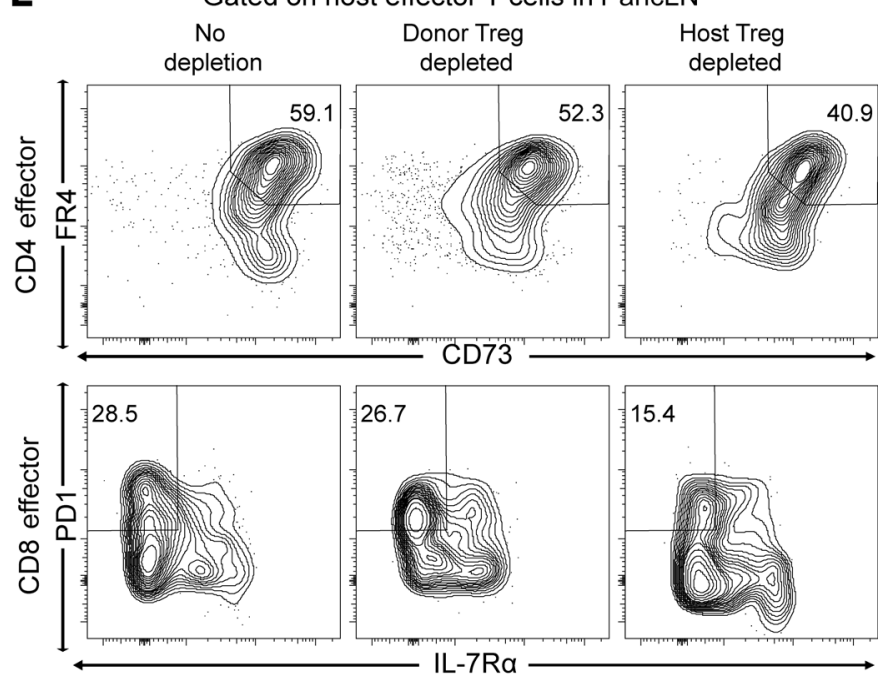

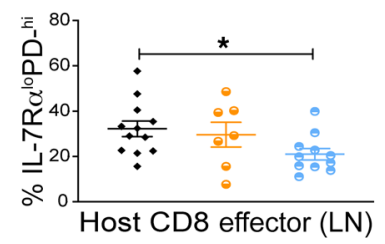

Figure 9. Both donor and host Tregs are required to maintain tolerance status. $\mathrm{H}-2^{\mathrm{b} / \mathrm{g} 7} \mathrm{Haplo}-\mathrm{MC}$ was induced using either donor or host mice carrying Foxp $3^{\text {OTR }}$. Forty-five to 60 days after HCT, diphtheria toxin (DT) was injected to chimeric mice every 3 days for 21 days. Only Foxp3 ${ }^{+}$Tregs from Foxp3 $3^{\text {DTR }}{ }_{-}$ carrying mice can express DT receptor and would be depleted. (A) Diagram of the HCT system that allows specific in vivo depletion of either donor- or host-type Tregs in mixed chimeras. (B) Efficacy of depletion of Tregs among spleen MNCs was evaluated at day 21. (C) Three weeks after the first injection, pancreas tissue from each group was collected to evaluate insulitis $(P<0.01$ when comparing no depletion with host Treg depleted or both donor and host Treg depleted; $P=0.17$ when comparing no depletion with donor Treg depleted). Depletion of either donor- or host-type Tregs led to moderate insulitis. Among WT mixed chimeras, more than $90 \%$ of mice were insulitis free in all the evaluated islets; this percentage dropped to $50 \%$ and $33 \%$ in donor-type Treg-depleted or host-type Treg-depleted chimeric mice, respectively. One representative is shown for 6-9 mice in each group $(P<0.0001$ when comparing no depletion to any other group). Scale bars: left panel, $200 \mu \mathrm{m}$; middle and right panels, $100 \mu \mathrm{m}$. (D and E) Representative patterns and mean \pm SEM of percentage of CD62L-CD44 ${ }^{\text {hi }}$ Tem cells among host-type Tcon cells and percentage of CD73 ${ }^{\text {hi }} F R 4^{\text {hi }}$ anergic cells among the Tem cells in the PancLNs of control Haplo-MC, Haplo-MC with depletion of donor-type Tregs, and Haplo-MC with depletion of host-type Tregs $(n=7-12)$. $P$ values were calculated using 1-way ANOVA; ${ }^{*} P<0.05,{ }^{* * *} P<0.001$. 
A

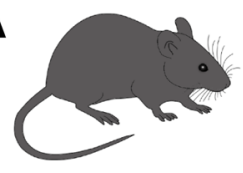

(B6×g7) $F_{1}$

$7.5 \times 10^{6}$

TCD-BM

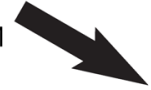

PD-L1 $1^{-1-}$ NOD

or WT NOD $5 \times 10^{6} \mathrm{TCD}-\mathrm{BM}$

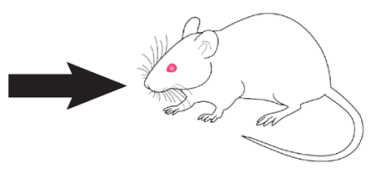

950 cGy irradiated WT NOD
B

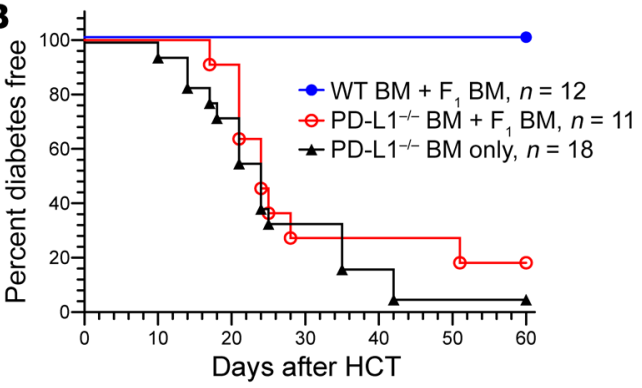

C Gated on host-type T cells in PancLN

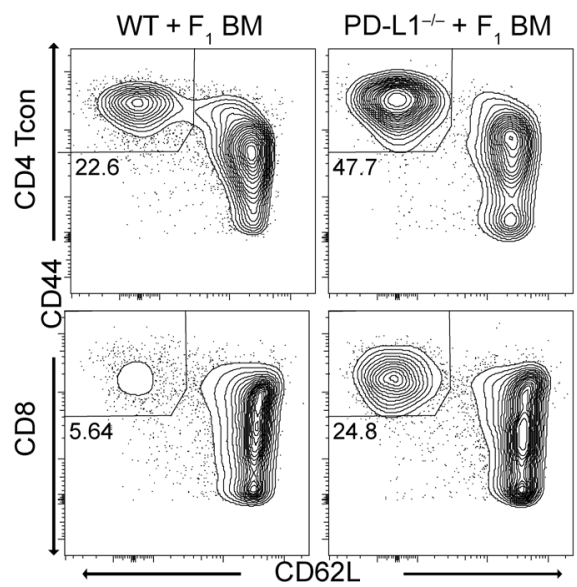

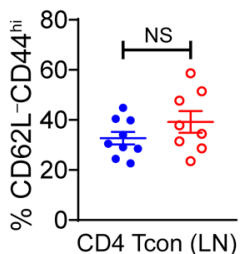

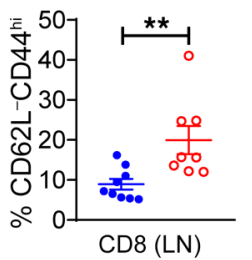

D Gated on host-type CD4+CD62L-CD44 hi T cells in PancLN
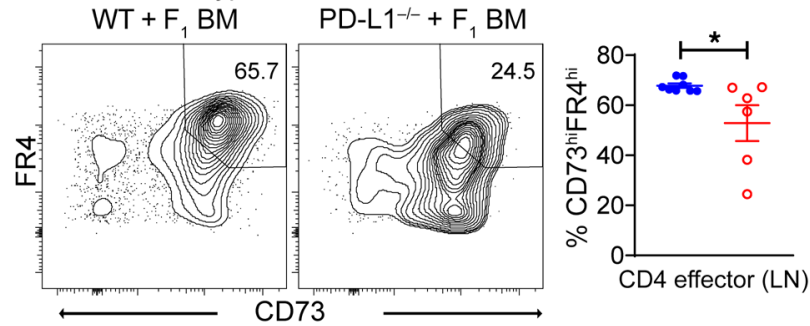

Gated on host-type T cells in pancreas
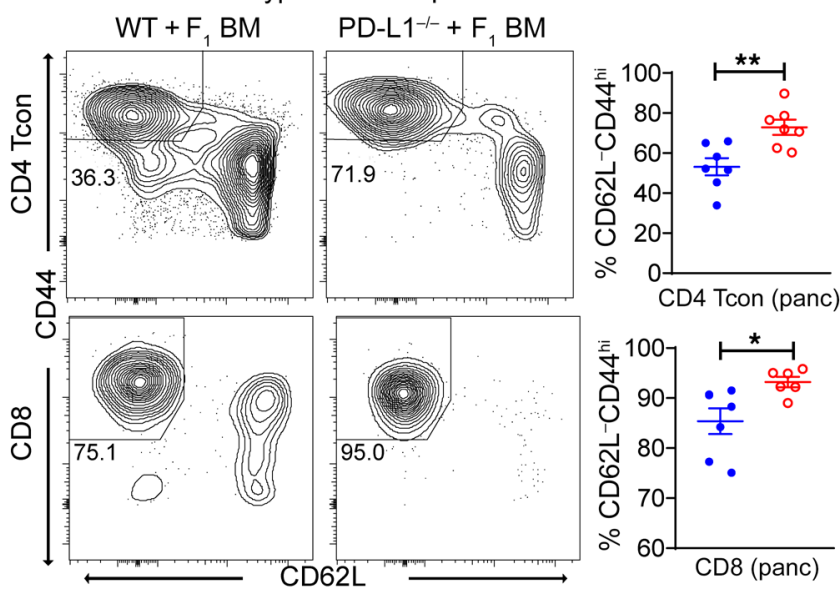

Gated on host-type CD4+CD62L-CD44 hi T cells in pancreas $\mathrm{WT}+\mathrm{F}_{1} \mathrm{BM} \quad \mathrm{PD}-\mathrm{L} 1^{-1-}+\mathrm{F}_{1} \mathrm{BM}$

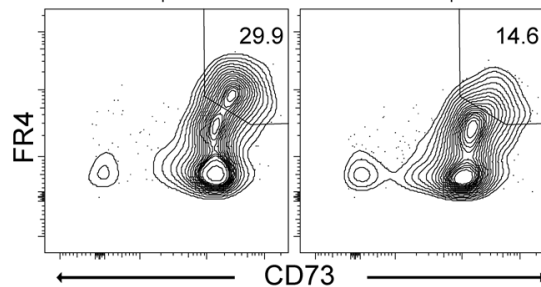

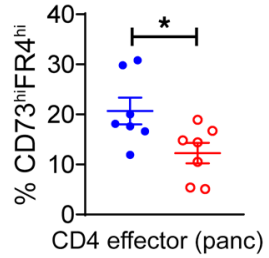

Figure 10. PD-L1 expressed on host-type hematopoietic cells is required to maintain tolerance. (A) TCD-BM cells from $H-2^{b / g^{7}} F_{1}$ were mixed with TCD-BM cells from either WT or PD-L1-1- NOD mice and injected into lethally irradiated 11- to 12-week-old WT NOD mice. (B) T1D development curves are shown for up to 60 days after HCT ( $n=11-18$, combined from 3 replicate experiments). (C) Forty-five to 60 days after HCT, percentage of host-type CD62L-CD44hi Tem cells among CD4+ Tcon or CD8 ${ }^{+}$Tcon cells in the PancLNs (left) and pancreas (right) was measured. Representative patterns and mean \pm SEM are shown ( $n=6-9)$. (D) Percentage of anergic CD73 ${ }^{\text {hiFR }} 4^{\text {hiCD4+ }}{ }^{+}$Tcon cells among CD62L-CD44hiCD4+ Tem cells in the PancLNs (left) and pancreas (right) ( $\left.n=6-7\right)$. $P$ values were calculated using unpaired 2 -tailed Student's $t$ tests; ${ }^{*} P<0.05,{ }^{* *} P<0.01$.

selection of host-type autoreactive thymocytes and generation of tTregs in the thymus, as well as associated with expansion of activated tTregs, upregulation of pDC expression of PD-L1, and preferential expansion of host-type pTregs in the periphery. On the other hand, we have also found that Haplo-MC in euthymic NOD mice established with myeloablative TBI conditioning and infusion of TCD-BM cells from the $\mathrm{H}-2^{\mathrm{b} / \mathrm{g} 7}$ or $\mathrm{H}-2^{\mathrm{s} / \mathrm{g} 7}$ donors was not able to eliminate insulitis, although it prevented clinical T1D development. We believe these observations are novel, and they support a theory proposed by Sykes and colleagues that cure of established autoimmunity by induction of mixed chimerism via allogeneic HCT requires (a) graft-versus-autoimmune-cells (GVA) activity; (b) thymic depletion; (c) peripheral anergy and deletion of autoreactive T cells; and (d) expansion of Tregs (12).
First, GVA activity in the absence of GVHD is important. Induction of Haplo-MC without causing GVHD in recipients conditioned with non-myeloablative ATG $+\mathrm{CY}+\mathrm{PT}$ requires infusion of $\mathrm{CD} 4^{+} \mathrm{T}$ cell-depleted hematopoietic transplant containing donor $\mathrm{CD} 8^{+} \mathrm{T}, \mathrm{NK}$, and other cells (22). And induction of Haplo-MC in recipients conditioned with myeloablative TBI requires infusion of donor TCD-BM cells (29). We observed that the former but not the latter approach was able to eliminate insulitis in Haplo-MC NOD mice, although both approaches prevented clinical T1D development. Therefore, infusion of $\mathrm{CD}^{+}{ }^{+} \mathrm{T}$ cell-depleted hematopoietic graft containing lymphocytes such as $\mathrm{CD} 8^{+} \mathrm{T}$ and NK cells that mediate GVA activity plays an important role in eliminating residual autoreactive $\mathrm{T}$ cells in the mixed chimeras. 
A

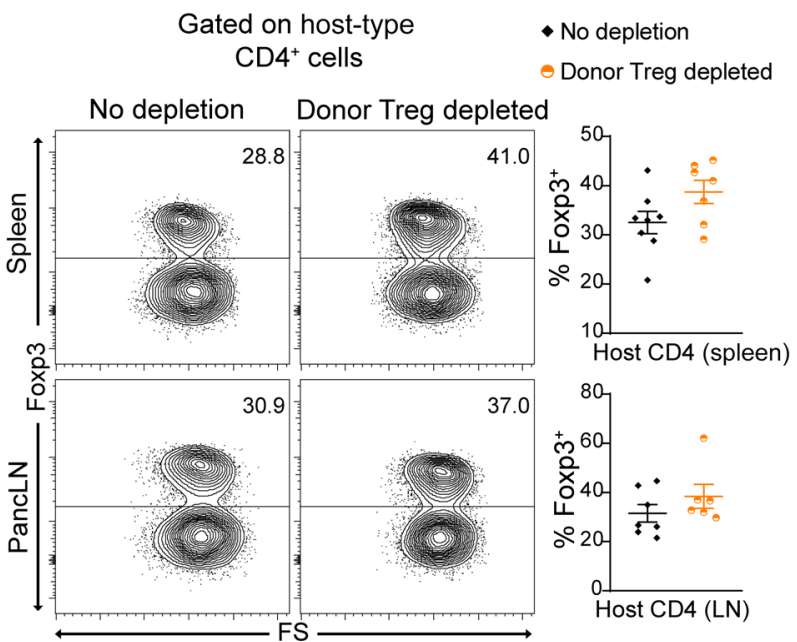

B
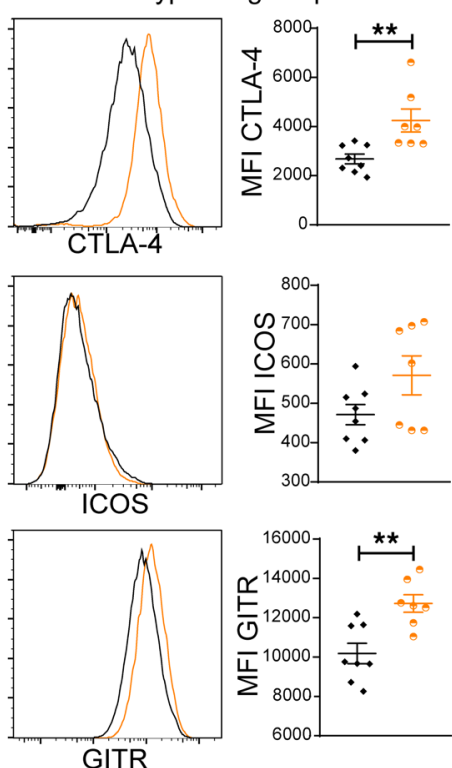

D Donor-type Treg in spleen
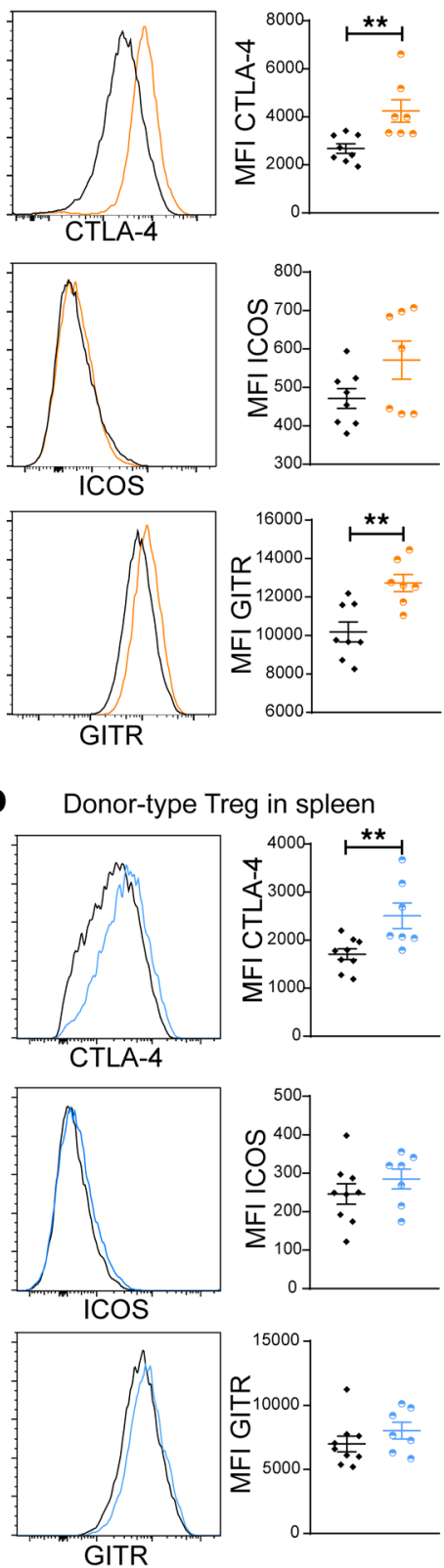
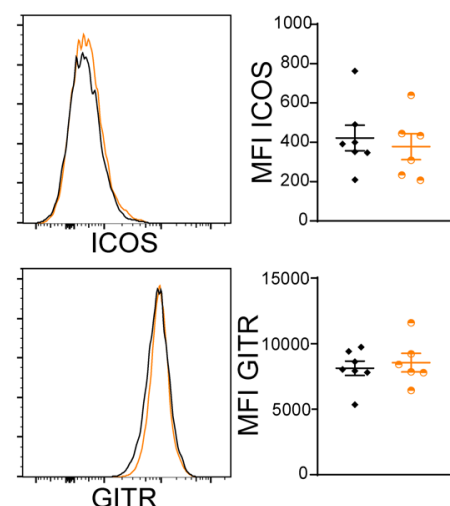

Donor-type Treg in PancLN

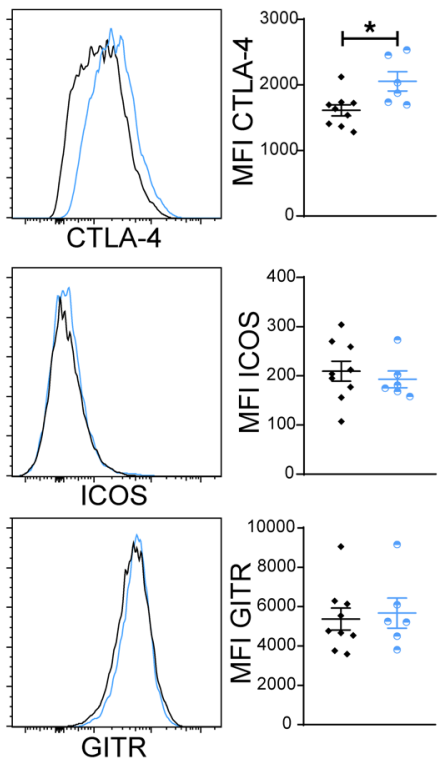

Figure 11. Percentage and surface receptor changes of donor- or host-type Tregs after depletion of host- or donor-type Tregs. Three weeks after depletion of Tregs by DT injection as described in Figure 9, percentage and surface receptors of donor- or host-type Tregs in the spleen (SPL) and PancLNs of NOD mice with $\mathrm{H}-2^{\mathrm{b} / \mathrm{g} 7}$ Haplo-MC were measured. (A and $\left.\mathbf{B}\right)$ Representative pattern and mean $\pm \mathrm{SEM}$ of percentage of host-type Tregs among hosttype CD4+ Tcon cells as well as expression levels of CTLA-4, ICOS, and GITR on host-type Tregs in the spleen and PancLNs of Haplo-MC NOD mice with or without depletion of donor-type Tregs $(n=6-9)$. (C and $\mathbf{D})$ Representative pattern and mean \pm SEM of percentage of donor-type Tregs among donor-type CD4+ Tcon cells as well as expression levels of CTLA-4, ICOS, and GITR on donor-type Tregs in spleen and PancLNs of Haplo-MC NOD mice with or without depletion of host-type Treg depletion $(n=6-9)$. $P$ values were calculated using unpaired 2-tailed Student's $t$ tests; ${ }^{*} P<0.05,{ }^{* *} P<0.01$.

Second, Haplo-MC with donors that possess autoimmunesusceptible $\mathrm{H}-2^{\text {s }}$ is as effective as Haplo-MC with donors that possess autoimmune-resistant $\mathrm{H}-2^{\mathrm{b}}$ in augmenting negative selection and generation of tTregs in the thymus. We observed that both $\mathrm{H}-2^{\mathrm{b} / \mathrm{g} 7}$ and $\mathrm{H}-2^{\mathrm{s} / \mathrm{g} 7}$ mixed chimeras showed partial depletion of host-type $\mathrm{CD} 4^{+} \mathrm{CD} 8^{+}(\mathrm{DP})$ thymocytes in WT NOD and near-complete depletion of DP thymocytes in BDC2.5 NOD with transgenic autoreactive $\mathrm{CD} 4^{+} \mathrm{T}$ cells. In contrast, there was a marked expansion of host-type tTregs among $\mathrm{CD} 4^{+} \mathrm{CD} 8^{-}$thymocytes in both WT and BDC2.5 NOD mice with $\mathrm{H}-2^{\mathrm{b} / \mathrm{g} 7}$ and $\mathrm{H}-2^{\mathrm{s} / \mathrm{g} 7}$ chimerism. Based on the partial deletion of DP thymocytes in the thymus of WT NOD mice and complete deletion of DP thymocytes in the thymus of BDC2.5 NOD mice with transgenic autoreactive T cells, we theorize that induction of Haplo-MC preferentially augments thymic negative selection of autoreactive $\mathrm{T}$ cells, with augmentation of tTreg generation in NOD mice.

It is particularly interesting that autoimmune-susceptible $\mathrm{H}-2^{\mathrm{s}}$ is as effective as autoimmune-resistant $\mathrm{H}-2^{\mathrm{b}}$ in augmenting nega- 
A Gated on host-type IgM-IgD-CD11 $\mathrm{c}^{+}$cells

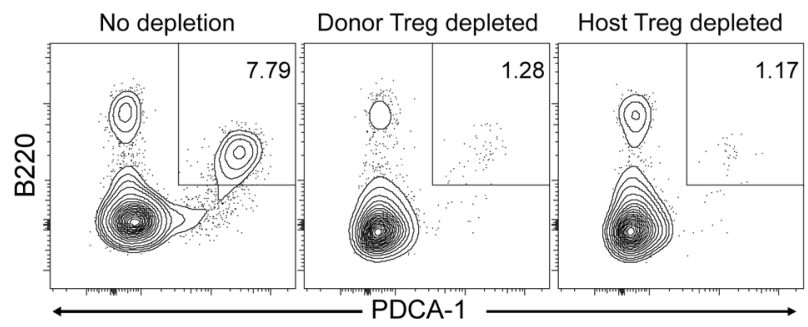

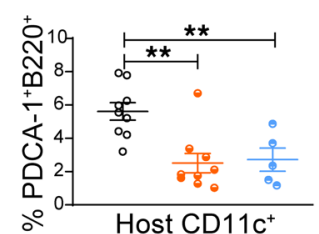

B Isotype

$\square$ No depletion

$\square$ Donor Treg depleted

Host PDCA1 ${ }^{+}$pDC
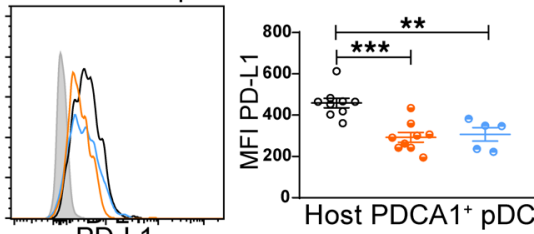

C Gated in host $\lg \mathrm{M}^{-} \lg \mathrm{D}^{-} \mathrm{CD} 11 \mathrm{C}^{+}$

\section{WT}
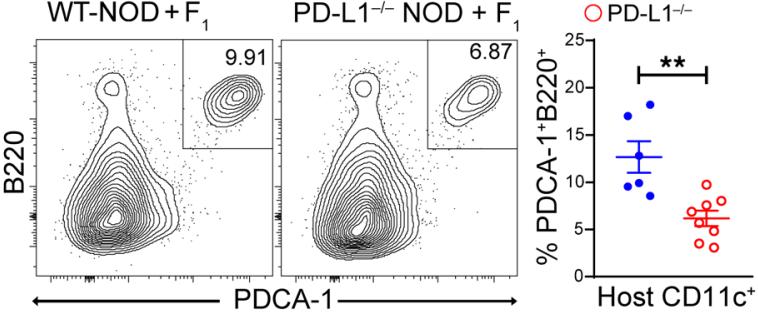

$\mathbf{E}$

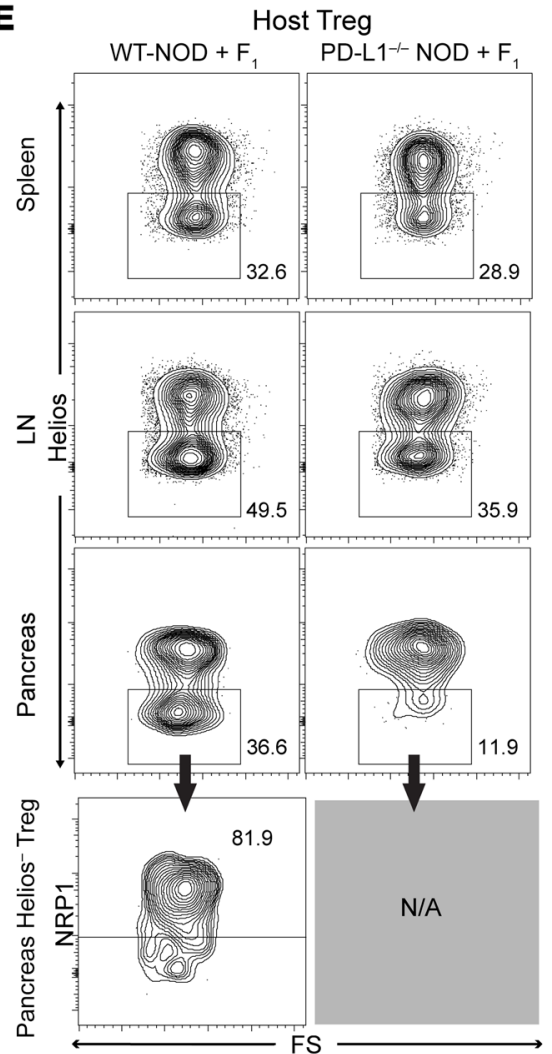

D Gated on host-type $\lg \mathrm{M}^{-} \lg \mathrm{D}^{-} \mathrm{CD} 11 \mathrm{C}^{+} \mathrm{B} 220^{-}$cells
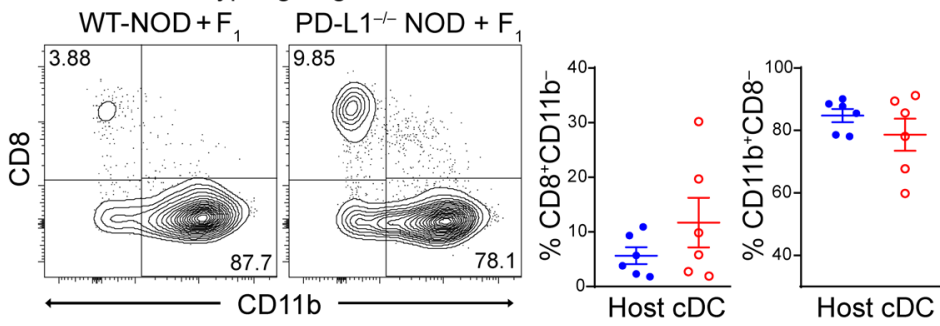

Donor Treg
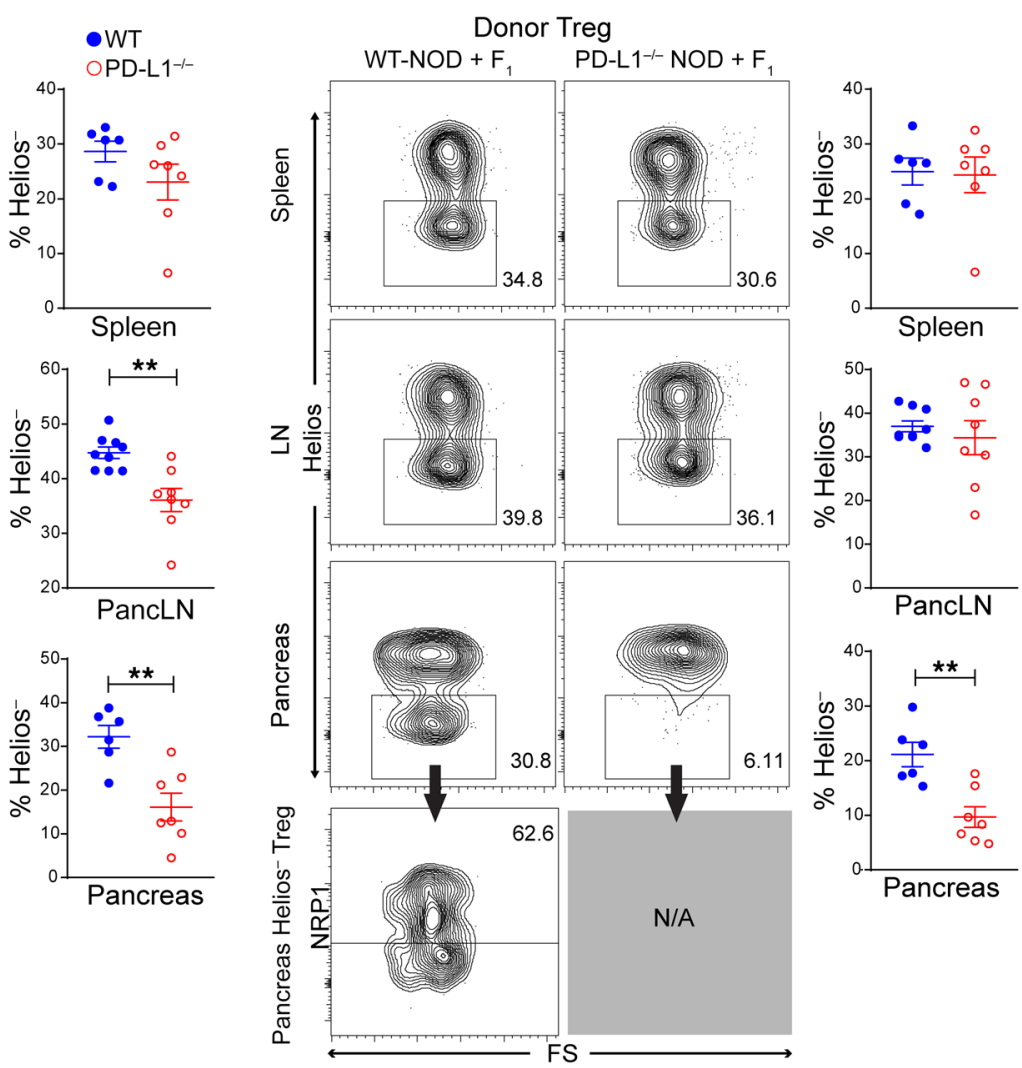

Figure 12. Interactions among donor- and host-type Tregs and PD-L1 $1^{\text {hi }}$ pDCs in the periphery of Haplo-MC NOD mice. Depletion of Tregs in Haplo-MC NOD mice was described in Figure 9, and establishing of Haplo-MC with host-type PD-L1/- hematopoietic cells was described in Figure 10. (A and B) Host-type pDCs and their expression of PD-L1 in the spleen (SPL) of Haplo-MC mice with or without depletion of donor- or host-type Tregs were compared. Representative pattern and mean \pm SEM of percentage of host-type B220+PDCA-1+ pDCs among IgM-IgD-CD11 $\mathrm{c}^{+}$cells and their PD-L1 expression levels are shown ( $n$ = 5-9). (C and D) Host-type CD220+PDCA-1+ pDC, CD8+ DC, and CD11 b+ DC subsets in the spleen of Haplo-MC mice with or without hematopoietic cell PD-L1 deficiency were measured. Representative pattern and mean \pm SEM of DC subsets are shown $(n=6-8)$. (E) Percentage of Helios ${ }^{-}$pTregs among host- or donor-type Tregs in the spleen, PancLNs, and pancreas was measured. Helios ${ }^{-N r p 1^{+}}$pTregs among Helios ${ }^{-}$pTregs in the pancreas were also measured. Representative patterns and mean \pm SEM are shown $(n=6-9)$. P values were calculated using 1-way ANOVA (A and B) or unpaired 2-tailed Student's $t$ tests (C-E); ${ }^{* *} P<0.01,{ }^{* *} P<0.001$. 
tive selection and expansion of host-type Tregs in the Haplo-MC NOD mice, despite being unable to augment negative selection or prevent T1D development when backcrossed to NOD mice (23). This may result from different $\mathrm{H}-2^{\mathrm{s}}$ cell distribution in $\mathrm{H}-2^{\mathrm{s} / \mathrm{g} 7}$ Haplo-MC NOD mice and $\mathrm{H}-2^{5 / 97}$ NOD mice. When $\mathrm{H}-2^{\mathrm{s}}$ is backcrossed to NOD mice, $\mathrm{H}-2^{\mathrm{s}}$ is expressed by both thymic cortical and medullary epithelial cells and DC cells. In this case, similarly to $\mathrm{I}-\mathrm{A}^{\mathrm{g} 7}$, I-A $\mathrm{A}^{\mathrm{s}}$ is involved in both positive and negative selection and manifests with defective negative selection (23). However, in the $\mathrm{H}-2^{\mathrm{g} 7 / \mathrm{s}}$ Haplo-MC, cortical epithelial cells express I-A $\mathrm{A}^{\mathrm{g} 7}$ without $\mathrm{I}-\mathrm{A}^{\mathrm{s}}$. Donor-type DCs that express $\mathrm{I}-\mathrm{A}^{\mathrm{g} 7 / \mathrm{s}}$ are present in the thymic medulla. For the thymocytes positively selected by only I-A $\mathrm{A}^{\mathrm{g} 7}$ in thymic cortex, MHC-II of I-As expressed by donor-type DCs in the medulla is equivalent to an "allo-MHC." TCRs have particular high binding affinity toward foreign MHC (56). The high binding affinity leads to augmentation of negative selection of host-type Tcon cells, in particular, host-type cross-reactive autoreactive Tcon cells. Our previous report showed that many autoreactive $\mathrm{T}$ cells are cross-reactive, and MHC-mismatched mixed chimeras preferentially deplete those cross-reactive T cells (32). On the other hand, the high binding affinity leads to augmentation of Foxp $3^{+}$tTreg generation (57). In addition, augmented deletion of autoreactive $\mathrm{T}$ cells, especially the cross-reactive autoreactive $\mathrm{T}$ cells, may make the residual autoreactive $\mathrm{T}$ cells susceptible to Treg suppression in the periphery. It was reported that $\mathrm{T}$ cells from NOD mice or T1D patients are resistant to Treg suppression (58).

Third, Haplo-MC preferentially augments deletion and induction of anergy of host-type T cells in the periphery of NOD mice. We observed that elimination of insulitis in euthymic and thymectomized WT NOD mice was associated with marked reduction in yield although not in percentage of CD $44^{\text {hi }}$ CD62 $\mathrm{L}^{-}$effector memory host-type T cells in the PancLNs and pancreas, as well as an increase in the percentage of CD73 ${ }^{\text {hi }} \mathrm{FR} 4^{\mathrm{hi}}$ anergic cells among residual host-type T cells. Haplo-MC in the euthymic NOD mice completely deleted autoantigen-specific HIP 2.5 tetramer ${ }^{+} \mathrm{CD} 4^{+}$ and NRP-V7 tetramer ${ }^{+} \mathrm{CD} 8^{+} \mathrm{T}$ cells among host-type $\mathrm{T}$ cells in the pancreas. Therefore, Haplo-MC can preferentially mediate deletion and anergy of host-type autoreactive $\mathrm{T}$ cells in the peripheral lymphoid tissues and autoimmune target organs.

Fourth, cure of autoimmunity with elimination of insulitis in euthymic and thymectomized Haplo-MC NOD mice is associated with differential expansion of tTregs and pTregs. T1D pathogenesis in NOD mice or T1D patients is associated with quantitative and qualitative defects in Tregs $(59,60)$ as well as Tcon cell resistance against Treg suppression $(58,61)$. We observed that cure with elimination of insulitis in the euthymic Haplo-MC was associated with expansion of both donor- and host-type CD62 $\mathrm{L}^{-}$ Helios $^{+}$tTregs as well as expansion of host-type CD62L-Helios $\mathrm{Nrp}^{+}$pTregs. In contrast, the cure in thymectomized Haplo-MC mice was only associated with expansion of both donor- and hosttype CD62L-Helios ${ }^{+}$tTregs. Therefore, we propose that (a) induction of Haplo-MC allows Tregs to suppress residual autoreactive T cells; and (b) activation and expansion of donor- and host-type tTregs are sufficient for control of residual autoreactive $\mathrm{T}$ cells in thymectomized Haplo-MC mice, but additional expansion of host-type pTregs is also required for control of residual autoreactive T cells in euthymic Haplo-MC mice.
Fifth, Haplo-MC in euthymic mice restores peripheral pDC tolerance status with upregulation of PD-L1 and augments pTreg expansion. It has been reported that Foxp 3 CD $73^{\text {hi }} F R 4^{\text {hi }}$ $\mathrm{Nrp}^{+} \mathrm{CD}^{+} \mathrm{T}$ cells can be the precursors of Foxp $3^{+}$pTregs (41); PD-L1 interaction with PD-1 on activated Tcon cells can augment their transdifferentiation into pTregs (62); PD-1 signaling also stabilized Foxp3 expression in pTregs (63); and PD-L1 interaction with CD80 on Tregs augmented Treg survival and expansion (64, 65). Consistently, Haplo-MC NOD mice showed expansion of both donor- and host-type Helios ${ }^{+} \mathrm{CD}_{62 \mathrm{~L}^{-}}$effector memory tTregs and expansion of Helios ${ }^{-}$CD62L-Nrp1 ${ }^{+}$pTregs in the spleen, PancLNs, and pancreas. In addition, we observed that the prevention of T1D development in BDC2.5 NOD mice was associated with expansion of antigen-specific pTregs. Furthermore, we observed that the expansion of Helios ${ }^{-} \mathrm{CD} 62 \mathrm{~L}^{-} \mathrm{Nrp} 1^{+}$pTregs was associated with expansion of anergic Foxp3 ${ }^{-} \mathrm{CD} 73^{\text {hi }} \mathrm{FR} 4^{\text {hi }} \mathrm{Nrp}^{+} \mathrm{CD}^{+} \mathrm{T}$ cells as well as upregulation of PD-L1 by host-type pDCs.

On the other hand, depletion of either donor- or host-type Tregs led to a marked reduction of host-type pDCs and their downregulation of PD-L1; in contrast, PD-L1 deficiency in hosttype hematopoietic cells resulted in marked reduction of host-type pDCs and severe loss of host-type pTregs in the PancLNs and pancreas of Haplo-MC NOD mice. Therefore, we propose that donortype and host-type tTregs from the thymus of Haplo-MC mice can restore the tolerance status of host-type peripheral pDCs by upregulating expression of PD-L1, and the PD-L1 interaction with PD-1 and CD80 on host-type autoreactive Tcon cells augments their transdifferentiation and expansion of antigen-specific pTregs.

In summary, we propose a systemic network of allo-MHCexpressing DCs, Tregs, and tolerogenic DCs in Haplo-MC NOD mice. As depicted in the graphical abstract, induction of Haplo-MC allows allo-MHC-expressing donor-type DC subsets to engraft in the host thymus, resulting in augmentation of negative selection of host-type autoreactive $\mathrm{T}$ cells and production of donor- and host-type tTregs. The tTregs are activated in the periphery and restore the tolerogenic features of host-type DCs (i.e., pDCs), including upregulation of their expression of PD-L1. Interactions between tolerogenic pDCs and residual autoreactive $\mathrm{T}$ cells via coinhibitory receptors, such as the interaction of PD-L1 with PD-1, augment autoreactive $\mathrm{T}$ cells to become anergic/exhausted $\mathrm{T}$ cells or antigen-specific pTregs. Furthermore, the Haplo-MC is a relatively stable system. Depleting either donor-type or host-type Tregs only causes moderate and self-limiting recurrence of insulitis in the absence of clinical T1D, because depletion of donor-type Tregs can lead to compensatory expansion of host-type Tregs, or vice versa. Therefore, induction of Haplo-MC can restore both central and peripheral tolerance in T1D mice.

Although we have observed preferential deletion of host-type autoreactive $\mathrm{T}$ cells in the thymus and preferential expansion of host-type pTregs that suppress autoimmunity in the periphery by observing the effects of Haplo-MC in WT NOD mice and in BDC2.5 NOD mice carrying transgenic autoreactive $\mathrm{T}$ cells, it remains unclear whether the effect of Haplo-MC on autoimmunity in NOD mice is a result of established mixed chimerism and/or is primarily an effect of the underlying autoimmunity. Dissecting these relations may require examination of the anergic/Treg axis in non-autoimmune versus autoimmune mice with Haplo-MC in future studies. 
We also propose that induction of Haplo-MC using nonmyeloablative conditioning of ATG $+\mathrm{CY}+\mathrm{PT}$ and infusion of $\mathrm{CD}^{+} \mathrm{T}$ cell-depleted hematopoietic transplant may have strong clinical potential as a curative therapy for refractory autoimmune diseases. First, induction of Haplo-MC is more effective than matched MC in reversal of autoimmunity. Induction of MHC (HLA)-matched mixed chimerism has been successfully achieved in humans to provide kidney transplantation immune tolerance ( 7 , 66). However, induction of MHC (HLA)-matched mixed chimerism has been reported to not prevent lupus flare in patients (7) and to not prevent T1D in mouse models (6). The current studies showed that induction of Haplo-MC effectively "cured" T1D in both euthymic and thymectomized T1D mice, even with a donor that possessed an autoimmune-susceptible MHC.

Second, the current regimen of induction of Haplo-MC is likely to be applicable in the clinic. Haploidentical HCT has been widely used in the clinic for treating nonmaligant hereditary hematological disorders (1). The current protocol for induction of Haplo-MC with the conditioning regimen of $\mathrm{ATG}+\mathrm{CY}+\mathrm{PT}$ and infusion of donor $\mathrm{CD}^{+} \mathrm{T}$ cell-depleted transplant is now under phase I safety clinical trial with sickle cell patients (NCT03249831), and we have obtained encouraging results. We have carried out trials with 2 sickle cell patients. We did not achieve detectable chimerism in the first patient. For the second patient, we increased the CY dose during conditioning. At the time of writing, the second patient had reached 180 days after HCT and had developed mixed chimerism for $\mathrm{CD} 34^{+}$stem cells in the $\mathrm{BM}$ as well as mixed chimerism for T, B, NK, and myeloid cells in the peripheral blood; the patient had predominantly donor-type healthy hemoglobin with little hemoglobin S and had total disappearance of clinical manifestation of sickle cell anemia with total absence of GVHD (J. Rosenthal et al., unpublished data).

Third, depletion of donor $\mathrm{CD}^{+}{ }^{+} \mathrm{T}$ cells in the hematopoietic transplant may be critical for induction of stable Haplo-MC. We understand that stable Haplo-MC is currently difficult to achieve in humans $(4,5,67)$. However, induction of stable Haplo-MC in humans may be achievable with the conditioning regimen of ATG $+\mathrm{CY}+\mathrm{PT}$ and infusion of $\mathrm{CD} 4^{+} \mathrm{T}$ cell-depleted hematopoietic transplant, and the depletion of donor $\mathrm{CD}^{+} \mathrm{T}$ cells may be critical. We reported that depletion of $\mathrm{CD}^{+}{ }^{+} \mathrm{T}$ cells allows tissue PD-L1 to tolerize infiltrating $\mathrm{CD}^{+} \mathrm{T}$ cells (25). It was necessary to use $\mathrm{CD}^{+} \mathrm{T}$ cell-depleted donor spleen cells to induce stable mixed chimerism in mice (22). Our recent studies also showed that addback of donor $\mathrm{CD}^{+} \mathrm{T}$ cells to transplants led to either graft rejection when a low dose of BM transplant was used, or complete chimerism when a high dose of donor BM transplant was used; and the presence of donor $\mathrm{CD} 4^{+} \mathrm{T}$ cells markedly reduced donor- and host-type T tolerance after HCT (Y. Zhu et al., unpublished data). Thus, depletion of donor $\mathrm{CD} 4^{+} \mathrm{T}$ cells in hematopoietic transplant may promote the establishing of stable Haplo-MC in non-myeloablatively conditioned recipients.

In conclusion, we have demonstrated that induction of Haplo$\mathrm{MC}$ with the non-myeloablative conditioning regimen of ATG + $\mathrm{CY}+\mathrm{PT}$ and depletion of donor $\mathrm{CD}^{+} \mathrm{T}$ cells in hematopoietic transplants cures established autoimmunity with elimination of insulitis in both euthymic and adult-thymectomized NOD mice. We have revealed a central and peripheral tolerance network in the
Haplo-MC NOD mice. These studies provide novel insights into the tolerance mechanisms in Haplo-MC and may help improve present protocols for treating patients with established autoimmune diseases. These studies also lay a basic foundation for translating induction of Haplo-MC in the clinic and for a clinical trial with autoimmune patients.

\section{Methods}

Mice. All recipient mice were purchased from either the National Cancer Institute animal production program (Frederick, Maryland, USA) or The Jackson Laboratory or were bred at the City of Hope Animal Research Center. Detailed information on each strain is given in Supplemental Table 1. All mice were housed in specific pathogen-free rooms in the City of Hope Animal Research Center.

Experimental procedures and materials. Induction of mixed chimerism with the cyclophosphamide (CY) plus pentostatin (PT) plus anti-thymocyte globulin (ATG) conditioning regimen, histopathology staining and insulitis evaluation, in vivo Treg depletion, induction of host lymphocyte $\mathrm{PD}-\mathrm{L1}^{-/}$mixed chimerism, isolation of lymphocytes from pancreas, release of DCs from spleen, flow cytometry analysis including tetramer staining, and details regarding antibodies are described in Supplemental Methods.

Statistics. Data are displayed as mean \pm SEM. Body weight and diabetes-free rate in different groups were compared using log-rank test. Insulitis in different groups was compared using $\chi^{2}$ test. Comparison of 2 means was done using unpaired 2-tailed Student's $t$ test, while comparison of multiple means was done using 1-way ANOVA; a $P$ value of less than 0.05 is considered as significant.

Software. Flow cytometry data were analyzed with FlowJo software version 10.5.3 (FlowJo LLC). Statistical analysis was prepared using GraphPad Prism version 8.0. The graphical abstract was created with BioRender.

Study approval. All animal procedures were approved by the IACUC of the Beckman Research Institute of City of Hope.

\section{Author contributions}

YL designed and performed research as well as prepared the manuscript. XW, YZ, MZ, UN, and SSS assisted in experiments. XZ is the home institute $\mathrm{PhD}$ advisor for YL and XW. ADR and SJF provided advice and financial support for the project as well as reviewed and edited the manuscript. DZ designed and supervised the research and wrote the manuscript.

\section{Acknowledgments}

We thank Lucy Brown and her staff at the City of Hope $(\mathrm{COH})$ Analytical Cytometry Core, Richard Ermel and his staff at the $\mathrm{COH}$ Animal Research Center, Peiguo Chu and his staff at the $\mathrm{COH}$ Pathology Core, and Brian Armstrong and his staff at the $\mathrm{COH}$ Light Microscopy Core for providing excellent services. We thank the NIH Tetramer Facility for providing HIP 2.5 and NRP-V7 tetramers for our studies. This work was generously supported by the Wanek Family; the Legacy Heritage Fund; the Thomas J. Beatson, Jr. Foundation Grant 2020-007; and private donations from Arthur and Judith Lubin. This work was also supported in part by the Cross-disciplinary Collaboration Projects Fund from Xinqiao Hospital of Army Medical University (2016D413 to XZ), National Key Research and Development Plan (2017YFA0105502 to XZ), 
Army Key Foundation (AWS14C014 to XZ), and the Social Undertaking and People's Livelihood Guarantee Science and Technology Innovation Fund of Chongqing (csts2016shms-ztzx10003 to XZ).

Address correspondence to: Defu Zeng or Arthur D. Riggs, Beckman Research Institute of City of Hope, 1500 East Duarte Road,
Duarte, California 91010, USA. Phone: 626.218.3587; Email: dzeng@coh.org (DZ). Phone: 626.218.3324; Email: ariggs@ coh.org (ADR). Or to: Xi Zhang, Medical Center of Hematology, Xinqiao Hospital of Army Medical University, 83 Xinqiao Avenue, Shapingba District, Chongqing, 400037, China. Phone: 86.023.68755609; Email: zhangxxi@sina.com.
1. Kanakry CG, Fuchs EJ, Luznik L. Modern approaches to HLA-haploidentical blood or marrow transplantation. Nat Rev Clin Oncol. 2016;13(2):132.

2. Strober S. Use of hematopoietic cell transplants to achieve tolerance in patients with solid organ transplants. Blood. 2016;127(12):1539-1543.

3. Chen YB, et al. Haploidentical hematopoietic cell and kidney transplantation for hematological malignancies and end-stage renal failure. Blood. 2019;134(2):211-215.

4. Kawai T, et al. HLA-mismatched renal transplantation without maintenance immunosuppression. N Engl J Med. 2008;358(4):353-361.

5. Leventhal JR, et al. Immune reconstitution/ immunocompetence in recipients of kidney plus hematopoietic stem/facilitating cell transplants. Transplantation . 2015;99(2):288-298.

6. Racine J, et al. Induction of mixed chimerism with MHC-mismatched but not matched bone marrow transplants results in thymic deletion of host-type autoreactive T-cells in NOD mice. Diabetes. 2011;60(2):555-564.

7. Scandling JD, et al. Chimerism, graft survival, and withdrawal of immunosuppressive drugs in HLA matched and mismatched patients after living donor kidney and hematopoietic cell transplantation. Am J Transplant. 2015;15(3):695-704.

8. Vanikar AV, et al. Hematopoietic stem cell transplantation in autoimmune diseases: the Ahmedabad experience. Transplant Proc. 2007;39(3):703-708.

9. Niu H, et al. The function of hematopoietic stem cells is altered by both genetic and inflammatory factors in lupus mice. Blood. 2013;121(11):1986-1994.

10. Nikolic T, Bunk M, Drexhage HA, Leenen PJ. Bone marrow precursors of nonobese diabetic mice develop into defective macrophage-like dendritic cells in vitro. JImmunol. 2004;173(7):4342-4351.

11. Lampeter EF, et al. Transfer of insulin-dependent diabetes between HLA-identical siblings by bone marrow transplantation. Lancet. 1993;341(8855):1243-1244.

12. Sykes M, Nikolic B. Treatment of severe autoimmune disease by stem-cell transplantation. Nature. 2005;435(7042):620-627.

13. Zeng D. Bridge between type 1 diabetes in mouse and man. Proc Natl Acad Sci U S A. 2017;114(41):10821-10823.

14. Pearson JA, Wong FS, Wen L. The importance of the Non Obese Diabetic (NOD) mouse model in autoimmune diabetes. J Autoimmun. 2016;66:76-88.

15. Klein L, Kyewski B, Allen PM, Hogquist KA. Positive and negative selection of the T cell repertoire: what thymocytes see (and don't see). Nat Rev Immunol. 2014;14(6):377-391.
16. Unanue ER. Antigen presentation in the autoimmune diabetes of the NOD mouse. Annu Rev Immunol. 2014;32:579-608.

17. Markees TG, et al. NOD mice have a generalized defect in their response to transplantation tolerance induction. Diabetes. 1999;48(5):967-974.

18. Liang Y, et al. Donor CD8 ${ }^{+} \mathrm{T}$ cells facilitate induction of chimerism and tolerance without GVHD in autoimmune NOD mice conditioned with anti-CD3 mAb. Blood. 2005;105(5):2180-2188.

19. Wang M, et al. Mixed chimerism and growth factors augment $\beta$ cell regeneration and reverse late-stage type 1 diabetes. Sci Transl Med. 2012;4(133):133ra59.

20. Zhang C, et al. Elimination of insulitis and augmentation of islet beta cell regeneration via induction of chimerism in overtly diabetic NOD mice. Proc Natl Acad Sci U S A . 2007;104(7):2337-2342.

21. Li N, et al. HDAC inhibitor reduces cytokine storm and facilitates induction of chimerism that reverses lupus in anti-CD3 conditioning regimen. Proc Natl Acad Sci U S A . 2008;105(12):4796-4801.

22. Wu L, et al. MHC-mismatched mixed chimerism augments thymic regulatory $\mathrm{T}$-cell production and prevents relapse of EAE in mice. Proc Natl Acad Sci U S A. 2015;112(52):15994-15999.

23. Schmidt D, Verdaguer J, Averill N, Santamaria P. A mechanism for the major histocompatibility complex-linked resistance to autoimmunity. J Exp Med. 1997;186(7):1059-1075.

24. Mariotti J, et al. The pentostatin plus cyclophosphamide nonmyeloablative regimen induces durable host $\mathrm{T}$ cell functional deficits and prevents murine marrow allograft rejection. Biol Blood Marrow Transplant. 2011;17(5):620-631.

25. Ni X, et al. PD-L1 interacts with CD80 to regulate graft-versus-leukemia activity of donor $\mathrm{CD}^{+} \mathrm{T}$ cells. J Clin Invest. 2017;127(5):1960-1977.

26. Haller MJ, et al. Low-dose anti-thymocyte globulin (ATG) preserves $\beta$-cell function and improves $\mathrm{HbA}_{1 \mathrm{c}}$ in new-onset type 1 diabetes. Diabetes Care. 2018;41(9):1917-1925.

27. Haller MJ, et al. Anti-thymocyte globulin/G-CSF treatment preserves $\beta$ cell function in patients with established type 1 diabetes. JClin Invest. 2015;125(1):448-455.

28. Dardenne M, Lepault F, Bendelac A, Bach JF. Acceleration of the onset of diabetes in NOD mice by thymectomy at weaning. Eur J Immunol. 1989;19(5):889-895.

29. Sykes M, Sheard MA, Sachs DH. Effects of T cell depletion in radiation bone marrow chimeras. II. Requirement for allogeneic $\mathrm{T}$ cells in the reconstituting bone marrow inoculum for subsequent resistance to breaking of tolerance. J Exp Med. 1988;168(2):661-673.

30. Zucchelli S, Holler P, Yamagata T, Roy M, Benoist C, Mathis D. Defective central tolerance induction in NOD mice: genomics and genetics. Immu- nity. 2005;22(3):385-396

31. Lesage S, Hartley SB, Akkaraju S, Wilson J, Townsend M, Goodnow CC. Failure to censor forbidden clones of CD4 T cells in autoimmune diabetes. JExp Med. 2002;196(9):1175-1188.

32. Racine JJ, Zhang M, Wang M, Morales W, Shen C, Zeng D. MHC-mismatched mixed chimerism mediates thymic deletion of cross-reactive autoreactive $\mathrm{T}$ cells and prevents insulitis in nonobese diabetic mice. JImmunol. 2015;194(1):407-417.

33. Kim SM, et al. Analysis of the paired TCR $\alpha$ - and $\beta$-chains of single human T cells. PLoS One. 2012;7(5):e37338.

34. Herbin O, et al. Medullary thymic epithelial cells and $\mathrm{CD} 8 \alpha^{+}$dendritic cells coordinately regulate central tolerance but CD $8 \alpha^{+}$cells are dispensable for thymic regulatory T cell production. J Autoimmun. 2016;75:141-149.

35. Hadeiba H, et al. Plasmacytoid dendritic cells transport peripheral antigens to the thymus to promote central tolerance. Immunity. 2012;36(3):438-450.

36. Baba T, Nakamoto Y, Mukaida N. Crucial contribution of thymic Sirp alpha+ conventional dendritic cells to central tolerance against bloodborne antigens in a CCR2-dependent manner. J Immunol. 2009;183(5):3053-3063.

37. Leventhal DS, et al. Dendritic cells coordinate the development and homeostasis of organ-specific regulatory T cells. Immunity. 2016;44(4):847-859.

38. Delong $\mathrm{T}$, et al. Pathogenic CD $4 \mathrm{~T}$ cells in type 1 diabetes recognize epitopes formed by peptide fusion. Science. 2016;351(6274):711-714.

39. Trudeau JD, et al. Prediction of spontaneous autoimmune diabetes in NOD mice by quantification of autoreactive T cells in peripheral blood. JClin Invest. 2003;111(2):217-223.

40. Martinez RJ, et al. Arthritogenic self-reactive $\mathrm{CD} 4^{+} \mathrm{T}$ cells acquire an $\mathrm{FR} 4^{\text {hi }} \mathrm{CD} 73^{\text {hi }}$ anergic state in the presence of Foxp3 ${ }^{+}$regulatory T cells. Jimmunol. 2012;188(1):170-181.

41. Kalekar LA, et al. CD4(+) T cell anergy prevents autoimmunity and generates regulatory $\mathrm{T}$ cell precursors. Nat Immunol. 2016;17(3):304-314.

42. Thornton AM, et al. Expression of Helios, an Ikaros transcription factor family member, differentiates thymic-derived from peripherally induced Foxp $3^{+}$T regulatory cells. JImmunol. 2010;184(7):3433-3441.

43. Lu L, Barbi J, Pan F. The regulation of immune tolerance by FOXP3. Nat Rev Immunol. 2017;17(11):703-717.

44. Kornete M, Sgouroudis E, Piccirillo CA. ICOSdependent homeostasis and function of Foxp3 $3^{+}$ regulatory $\mathrm{T}$ cells in islets of nonobese diabetic mice. JImmunol. 2012;188(3):1064-1074.

45. Wyss L, et al. Affinity for self antigen selects Treg cells with distinct functional properties. Nat Immunol. 2016;17(9):1093-1101.

46. Herman AE, Freeman GJ, Mathis D, Benoist 
C. $\mathrm{CD} 4{ }^{+} \mathrm{CD} 25^{+} \mathrm{T}$ regulatory cells dependent on ICOS promote regulation of effector cells in the prediabetic lesion. J Exp Med. 2004;199(11):1479-1489.

47. Wing K, et al. CTLA-4 control over Foxp $3^{+}$regulatory $\mathrm{T}$ cell function. Science. 2008;322(5899):271-275.

48. Li H, Shi B. Tolerogenic dendritic cells and their applications in transplantation. Cell Mol Immunol. 2015;12(1):24-30.

49. Tokita D, et al. High PD-L1/CD86 ratio on plasmacytoid dendritic cells correlates with elevated T-regulatory cells in liver transplant tolerance. Transplantation. 2008;85(3):369-377.

50. Ben Nasr M, et al. PD-L1 genetic overexpression or pharmacological restoration in hematopoietic stem and progenitor cells reverses autoimmune diabetes. Sci Transl Med.2017;9(416):eaam7543.

51. Zhang M, et al. MHC-mismatched mixed chimerism restores peripheral tolerance of noncrossreactive autoreactive T cells in NOD mice. Proc Natl Acad Sci U S A. 2018;115(10):E2329-E2337.

52. Keir ME, et al. Tissue expression of PD-L1 mediates peripheral T cell tolerance. J Exp Med. 2006;203(4):883-895.

53. Dendrou CA, Petersen J, Rossjohn J, Fugger L. HLA variation and disease. Nat Rev Immunol.
2018;18(5):325-339.

54. Gutierrez-Arcelus M, Rich SS, Raychaudhuri S. Autoimmune diseases - connecting risk alleles with molecular traits of the immune system. Nat Rev Genet. 2016;17(3):160-174.

55. Atkinson MA, Eisenbarth GS, Michels AW. Type 1 diabetes. Lancet. 2014;383(9911):69-82.

56. Balakrishnan A, Morris GP. The highly alloreactive nature of dual TCR T cells. Curr Opin Organ Transplant. 2016;21(1):22-28.

57. Millar DG, Ohashi PS. Central tolerance: what you see is what you don't get! Nat Immunol. 2016;17(2):115-116.

58. Schneider A, Rieck M, Sanda S, Pihoker C, Greenbaum C, Buckner JH. The effector T cells of diabetic subjects are resistant to regulation via $\mathrm{CD} 4^{+} \mathrm{FOXP}^{+}$regulatory T cells. JImmunol. 2008;181(10):7350-7355.

59. Ferreira C, Singh Y, Furmanski AL, Wong FS, Garden OA, Dyson J. Non-obese diabetic mice select a low-diversity repertoire of natural regulatory T cells. Proc Natl Acad Sci U S A. 2009;106(20):8320-8325.

60. Okubo Y, Torrey H, Butterworth J, Zheng H, Faustman DL. Treg activation defect in type 1 diabetes: correction with TNFR2 agonism. Clin Transl Immunology. 2016;5(1):e56.
61. D'Alise AM, et al. The defect in T-cell regulation in NOD mice is an effect on the T-cell effectors. Proc Natl Acad Sci U S A. 2008;105(50):19857-19862.

62. Amarnath S, et al. The PDL1-PD1 axis converts human TH1 cells into regulatory T cells. Sci Transl Med. 2011;3(111):111ra120.

63. Stathopoulou C, et al. PD-1 inhibitory receptor downregulates asparaginyl endopeptidase and maintains Foxp3 transcription factor stability in induced regulatory T cells. Immunity. 2018;49(2):247-263.e7.

64. Ellestad KK, Thangavelu G, Ewen CL, Boon L, Anderson CC. PD-1 is not required for natural or peripherally induced regulatory $\mathrm{T}$ cells: severe autoimmunity despite normal production of regulatory T cells. Eur JImmunol. 2014;44(12):3560-3572.

65. Yi T, et al. Host APCs augment in vivo expansion of donor natural regulatory $\mathrm{T}$ cells via B7H1/B7.1 in allogeneic recipients. J Immunol. 2011;186(5):2739-2749.

66. Zuber J, Sykes M. Mechanisms of mixed chimerism-based transplant tolerance. Trends Immunol. 2017;38(11):829-843.

67. Spinner MA, et al. HLA-mismatched unrelated donor transplantation using TLI-ATG conditioning has a low risk of GVHD and potent antitumor activity. Blood Adv. 2017;1(17):1347-1357. 